\title{
Review of long period fiber gratings written by $\mathrm{CO}_{2}$ laser
}

\author{
Yiping Wang \\ Optoelectronics Research Centre, University of Southampton, Southampton, SO17 1BJ, U.K. \\ Corresponding author: E-mail: ypwang@ china.com, Tel: +44-23-80592699; Fax: +44-23-80593149
}

\begin{abstract}
This paper presents a systematic review of long period fiber gratings (LPFGs) written by the $\mathrm{CO}_{2}$ laser irradiation technique. Firstly, various fabrication techniques based on $\mathrm{CO}_{2}$ laser irradiations are demonstrated to write LPFGs in different types of optical fibers such as conventional glass fibers, solidcore photonic crystal fibers, and air-core photonic bandgap fibers. Secondly, possible mechanisms, e.g. residual stress relaxation, glass structure changes, and physical deformation, of refractive index modulations in the $\mathrm{CO}_{2}$-laser-induced LPFGs are analysed. Thirdly, asymmetrical mode coupling, resulting from single-side laser irradiation, is discussed to understand unique optical properties of the $\mathrm{CO}_{2}$-laser-induced LPFGs. Fourthly, several pre- and post-treatment techniques are proposed to enhance the efficiency of grating fabrications. Fifthly, sensing applications of the $\mathrm{CO}_{2}$-laser-induced LPFGs are investigated to develop various LPFG-based temperature, strain, bend, torsion, pressure, and biochemical sensors. Finally, communication applications of the $\mathrm{CO}_{2}$-laser-induced LPFGs are investigated to develop various LPFG-based band-rejection filters, gain equalizers, polarizers and couplers.
\end{abstract}

\section{INTRODUCTION}

Optical fiber gratings already play a vital role in the field of optical communications and sensors. There are two types of in-fiber gratings: fiber Bragg gratings (FBGs) with periodicities of the order of the optical wavelength [1-4] and long period fiber gratings (LPFGs) with periodicities of several hundred wavelengths [5-15]. Since Hill et al. [1] and Vengsarkar et al. [5] wrote the first FBG and LPFG in conventional glass fibers in 1978 and 1996, respectively, the fabrications and applications of in-fiber gratings have achieved rapid developments. Various fabrication methods, such as ultraviolet (UV) laser exposure [5-15], $\mathrm{CO}_{2}$ laser irradiation [16-29], electric arc discharge [30-37], femtosecond laser exposure [38-43], mechanical microbends [4451], etched corrugations [52-57], and ion beam implantation [58-60], have been demonstrated to write LPFGs in different types of optical fibers. Numerous LPFG-based devices have also been developed to realize their sensing and communication applications [4, 14, 22].

Davis et al. reported what is believed to be the first example of gratings written by the $\mathrm{CO}_{2}$ laser irradiation technique in a conventional glass fiber in 1998 [16, 17]. Compared with the UV laser exposure technique, the $\mathrm{CO}_{2}$ laser irradiation technique is much more flexible and low cost because no photosensitivity and any other pretreated process are required to write a grating in the glass fibers [16-29]. Moreover, the $\mathrm{CO}_{2}$ laser irradiation process can be controlled to generate complicated grating profiles via the well-known point-to-point technique without any expensive masks. This technique could be, hence, used to write LPFGs in almost all types of fibers including pure-silica photonic crystal fibers (PCFs). Liu et al. presented recent development on the $\mathrm{CO}_{2}$-laser-induced LPFGs [29]. The most exciting and latest development of the $\mathrm{CO}_{2}$ laser irradiation technique is to successfully write the first LPFG in an air-core photonic bandgap fiber $(\mathrm{PBF})$ by the use of a focused $\mathrm{CO}_{2}$ laser beam to periodically perturb/deform the air holes along the fiber axis [26]. Such breakthrough science opens the door to PBF-based gratings and gratingbased devices in air-core PBFs. 
This paper presents a systematic review of LPFGs written by the $\mathrm{CO}_{2}$ laser irradiation technique in different types of optical fibers. The methods for writing LPFGs in conventional glass fibers, solid-core PCFs, and air-core PBFs with a $\mathrm{CO}_{2}$ laser are presented first in Section II. Then possible mechanisms, e.g. residual stress relaxation, glass structure changes, and physical deformation, of refractive index modulations in the $\mathrm{CO}_{2}$-laser-induced LPFGs are analysed in Section III. Asymmetrical mode coupling in such LPFGs is discussed in Section IV. Pretreatment techniques, such as hydrogen loading and applying prestrain, and post-treatment techniques, such as applying tensile strain and changing temperature, are proposed to enhance the efficiency of grating fabrications in Section V. Subsequently, the sensing applications, such as temperature, strain, bend, torsion, pressure, and biochemical sensors, and the communication applications, such as band-rejection filters, gain equalizers, polarizers and couplers, of the $\mathrm{CO}_{2^{-}}$ laser-induced LPFGs are investigated in Sections VI and VII, respectively. The paper is concluded in Section VIII.

\section{II. $\mathrm{CO}_{2}$ LASER IRRADIATION TECHNIQUES}

Since Davis et al. reported the first $\mathrm{CO}_{2}$-laser-induced $\mathrm{LPFG}$ in a conventional glass fiber in 1998 [16, 17], various $\mathrm{CO}_{2}$ laser irradiation techniques have been demonstrated and improved to write high-quality LPFGs in different types of optical fibers, such as conventional glass fibers, $\mathrm{PCFs}$, and PBFs, and to achieve unique grating properties. This section reviews the development of the $\mathrm{CO}_{2}$ laser irradiation techniques for writing LPFGs in conventional glass fibers, solid-core PCFs, and air-core PBFs.

\section{A. To write LPFGs in conventional glass fibers}

Typically, in most of LPFG fabrication setups employing a $\mathrm{CO}_{2}$ laser $[16,17,27,61]$, as shown in Fig. 1, the fiber is periodically moved along its axis direction via a computer-controlled translation stage, and the $\mathrm{CO}_{2}$ laser beam irradiates periodically the fiber through a shutter controlled by a same computer. A light source and an optical spectrum analyzer are employed to monitor the evolution of the grating spectrum during the laser irradiation. This is a typical pointto-point technique for writing a grating in an optical fiber. Such a LPFG fabrication system usually requires an exactly controlling of both the shutter and the translation stage to achieve a good simultaneousness of the laser irradiation and the fiber movement. Additionally, the vibration of the employed fiber, resulting from the periodic movement of the fiber, could occur during the irradiation of the $\mathrm{CO}_{2}$ laser beam, which is of disadvantage to the stability and repeatability of the grating fabrication.

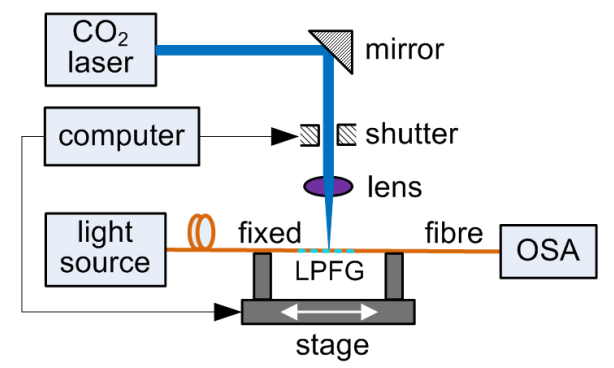

Fig. 1 Schematic diagram of a normal LPFG fabrication system based on the typical point-to-point technique employing a $\mathrm{CO}_{2}$ laser.

Rao et al. demonstrated, for the first time, a novel grating fabrication system based on 2dimentional scanning of the $\mathrm{CO}_{2}$ laser beam [21, 22], as shown in Fig. 2. One end the employed fiber is fixed and another end is attached to a small weight to provide a constant prestrain in the 
fiber, thus enhancing the efficiency of the grating fabrication, as discussed below in Section V. The focused high-frequency $\mathrm{CO}_{2}$ laser pulses scanned periodically across the employed fiber along ' $\mathrm{X}$ ' direction and then shifted a grating pitch along ' $\mathrm{Y}$ ' direction, i.e. the fiber axis, to create next grating period by means of 2-dimensional optical scanners under the computer control. Compared with typical point-to-point fabrication systems [16, 17, 27, 61], no exactly simultaneous controlling is required in such a system because the employed fiber is not periodically moved along the fiber axis. Such a system can write high-quality LPFGs with a nearly zero insertion loss. A similar fabrication setup was also demonstrated to write a LPFG with a $\mathrm{CO}_{2}$ laser, in which the laser beam, however, scanned one-dimensionally across the fiber that was periodically moved along the fiber axis [62].

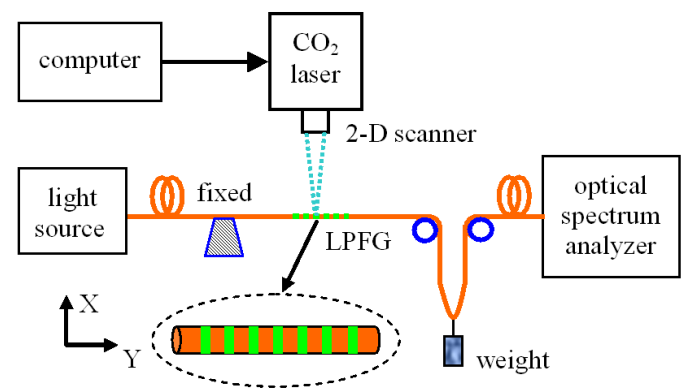

Fig. 2 Schematic diagram of LPFG fabrication system based on 2-dimentional scanning of focused high-frequency $\mathrm{CO}_{2}$ laser pulses [21].

The author recently developed an improved LPFG fabrication system based on the point-topoint technique employing a $\mathrm{CO}_{2}$ laser, as shown in Fig. 3, combining with the advantages of the two fabrication systems illustrated in Figs. 1 and 2. The $\mathrm{CO}_{2}$ laser beam is, through a shutter and a mirror, focused on the fiber by a cylindrical lens with a focus length of $254 \mathrm{~mm}$. Both the mirror and the lens are mounted on a linear air-bearing motor stage (ABL 1500 from Aerotech). A Labview program has been developed to control simultaneously the operations of both the linear motor stage and the shutter so that the fiber is exposed once as soon as the focused laser beam is shifted by a grating pitch via the mirror. In other words, the fiber is not periodically moved in this system, which overcomes the disadvantage of the fiber vibration, resulting from periodic movement of the fiber, in normal point-to-point grating fabrication setups shown in Fig. 1. A desired LPFG can be achieved as soon as the required fabrication parameters, such as grating pitch, number of grating periods, exposure time per period, and number of exposure cycles, are input via an operation interface illustrated in Fig. 3(b). Such an improved fabrication system could potentially be integrated with a fiber drawing tower to write continuously a large number of LPFGs during drawing a fiber. 
(a)
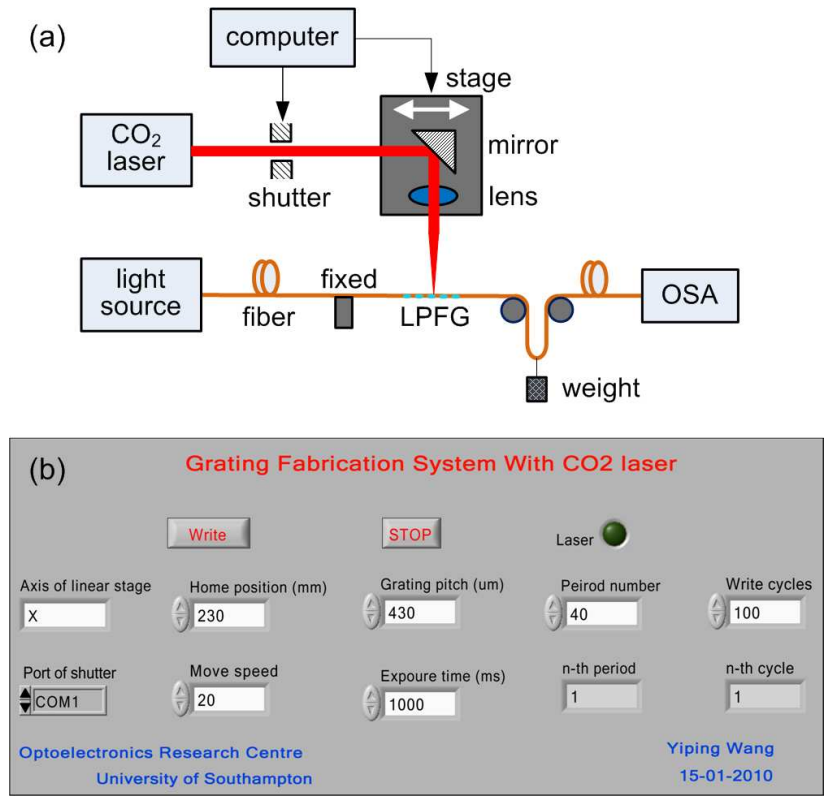

Fig. 3 (a) Schematic diagram of an improved LPFG fabrication system employing a $\mathrm{CO}_{2}$ laser, (b) Operation interface of the fabrication system.

$\mathrm{CO}_{2}$ laser irradiation may cause unexpected physical deformation, resulting from laser heating, of fiber structures during LPFG fabrication. Such physical deformations are usually avoided to decrease the insertion loss of the written LPFGs during early grating fabrications with a $\mathrm{CO}_{2}$ laser $[16,17,21]$. Wang et al. reported a novel technique for writing an asymmetric LPFG by means of carving periodic grooves on the surface of an optical fiber with a focused $\mathrm{CO}_{2}$ laser beam [23], as shown in Fig. 4. Physical deformations, i.e. periodic grooves, in such an asymmetric LPFG, do not cause a large insertion loss because these grooves are totally confined within the outer cladding and have no influence on the light transmission in the fiber core. Moreover, such grooves enhance the efficiency of grating fabrication and introduce unique optical properties, e.g. extremely high strain sensitivity, into the gratings [23, 63]. Further investigations discover that the insertion loss of LPFGs is mainly due to the nonperiodicity and the disorder of refractive index modulations in the gratings.

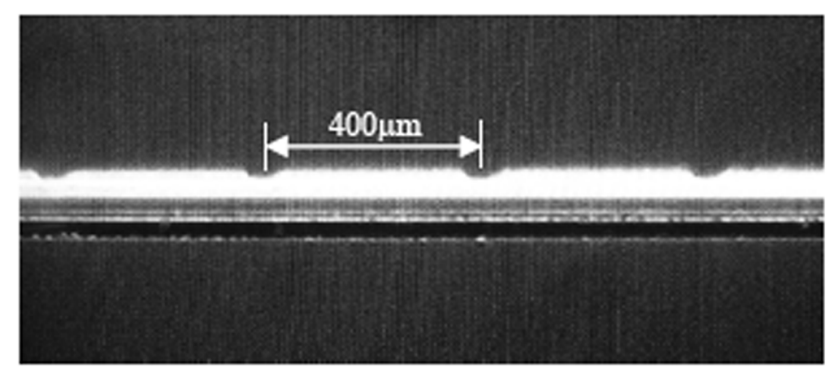

Fig. 4 Photograph of an asymmetric LPFG with periodic grooves [23].

Additionally, a few other $\mathrm{CO}_{2}$ laser irradiation techniques have been demonstrated to write special LPFGs. For example, (1) an edge-written technique was reported to write special LPFGs with high-frequency $\mathrm{CO}_{2}$ laser pulses [64-66]. Refractive index disturbance in such an edgewritten LPFG mainly occurs in the edge region of the fiber cladding rather than in the fiber core. 
(2) A helical LPFG was fabricated in an optical fiber that was continuously rotates and moves along the fiber axis during $\mathrm{CO}_{2}$ laser irradiation [67]. Compared with a conventional LPFG, a helical LPFG has a very low polarization dependent loss (PDL) due to a screw-type index modulation in this grating, which thus could be a potential technique for achieving a LPFG with a low PDL. (3) Microtaper-based LPFGs were also fabricated by means of tapering periodically a conventional glass fiber with a focused $\mathrm{CO}_{2}$ laser beam $[19,68-70]$. Negative temperature coefficient of the resonant wavelength was observed in the microtaper-based LPFGs [68].

Apart from conventional single mode fibers (SMFs), there have been a number of studies on $\mathrm{CO}_{2}$-laser writing of LPFGs in boron-doped fibers [71-75]. The grating writing efficiency can be enhanced with a fiber annealed at a sufficiently high temperature [29, 71, 72]. Compared with normal UV laser exposure technique, the $\mathrm{CO}_{2}$ laser irradiation technique is easily used to write special gratings such as phase-shifted LPFGs [28, 69], chirped LPFGs [76], complicated apodized LPFGs [77], grating pairs [62], and ultra-long period fiber gratings with a period of up to several millimeters [78-80]. LPFGs have also been successfully achieved with a $\mathrm{CO}_{2}$ laser during the fiber-drawing process [81]. So it is possible for the $\mathrm{CO}_{2}$ laser irradiation technique to continuously write numerous LPFGs with high quality and low cost in an optical fiber to develop potential distributed sensing systems and communication applications. By the way, $\mathrm{CO}_{2}$ laser irradiation can be used to enhance the UV photosensitivity of $\mathrm{GeO}_{2}: \mathrm{SiO}_{2}$ optical fibers before grating writing [82].

\section{B. To write LPFGs in solid-core PCFs}

Over the past decade, PCFs have attracted a great deal of interest due to their unique microstructures and optical properties [83, 84]. Since Eggleton et al. reported the first grating in a photosensitive PCF with a Ge-doped core in 1999 [12], a large number of gratings have been written in different types of PCFs with or without photosensitivity by the use of various fabrication techniques such as UV laser exposure [13], $\mathrm{CO}_{2}$ laser irradiation [20, 24, 25, 27], electric-arc discharge [34], femtosecond laser exposure [41, 43], and two-photon absorption [85]. UV laser exposure is a common technique for writing a FBG/LPFG in a Ge-doped PCF with a photosensitivity $[12,86,87]$. In contrast, $\mathrm{CO}_{2}$ laser irradiation is a highly efficient, low cost technique for writing a LPFG in a pure-silica PCF without photosensitivity [20, 24, 25, 27].

Kakarantzas et al. reported, as shown in Fig. 5, the first example of structural LPFGs written in pure-silica solid-core PCFs $[20,88]$. The gratings are realized by periodic collapse of air holes in the PCF via heat treatment with a $\mathrm{CO}_{2}$ laser. The resulting periodic hole-size perturbation produces core-to-cladding-mode conversion, thus creating a novel LPFG in the PCF [20]. This technique, combining with periodic mechanical twisting, can be used to fabricate a rocking filter in a polarization-maintaining PCF [88].

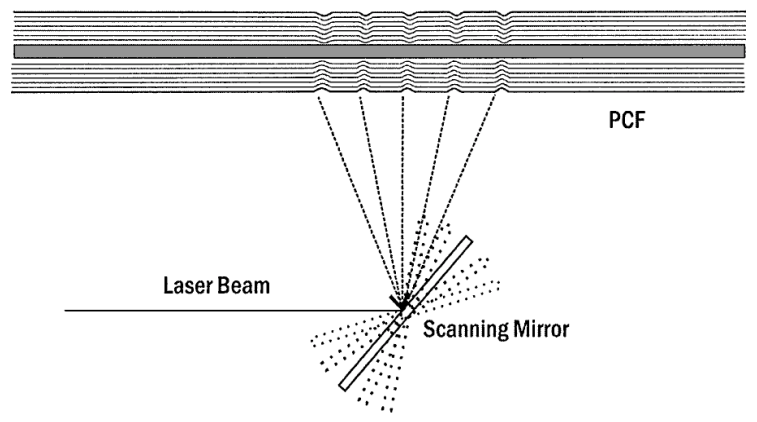

Fig. 5 First LPFG written in a pure-silica solid-core PCF with a $\mathrm{CO}_{2}$ laser [20]. 
As shown in Fig. 6, an asymmetrical LPFG with periodic grooves was written in a puresilica large-mode-area PCF by the use of a focused $\mathrm{CO}_{2}$ laser beam $[24,25]$. The repeated scanning of the focused $\mathrm{CO}_{2}$ laser beam creates a local high temperature in the fiber, which leads to the collapse of air holes and the gasification of $\mathrm{SiO}_{2}$ on the fiber surface. Consequently, periodic grooves with a depth of about $15 \mu \mathrm{m}$ and a width of about $50 \mu \mathrm{m}$ are created on the fiber, as shown in Fig. 6(b). Such grooves, especially collapse of air holes, induce periodic refractive index modulations along the fiber axis due to the well-known photoelastic effect, thus creating a LPFG in the PCF. This asymmetrical LPFG has unique optical properties, e.g. high strain sensitivity, low temperature sensitivity and high polarization dependence, as discussed below in Sections VI and VII.

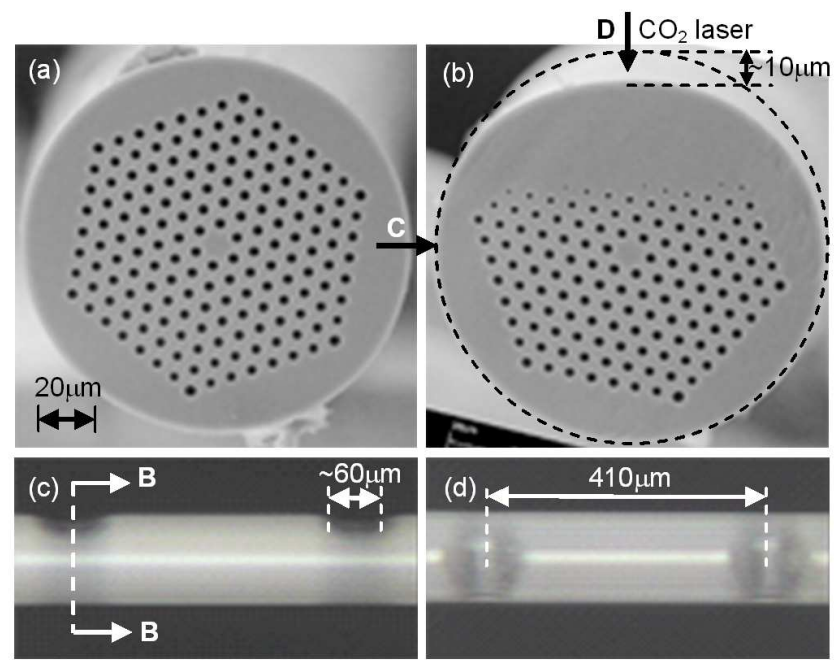

Fig. 6 Asymmetrical LPFG with periodic grooves in a pure-silica PCF [25]

A highly compact LPFG with only 8 periods and a short total length of $2.8 \mathrm{~mm}$ was written in a pure-silica large-mode-area PCF by the common point-by-point technique employing a $\mathrm{CO}_{2}$ laser [27], in which clear physical deformation was also observed. In contrast, another LPFG without geometrical deformation and fiber elongation was written in an endlessly single-mode PCF by periodic stress relaxation resulting from $\mathrm{CO}_{2}$ laser irradiation [89]. Moreover, a LPFG pair has been successfully created in a pure-silica PCF with a $\mathrm{CO}_{2}$ laser to develop a stain sensor [90]. A novel coupled local-mode theory could be used to model and analyze this type of PCFbased LPFGs with periodic collapses of air holes [91]. Such a theory is based on calculating the variations of local-mode profiles and propagation constants over the perturbed regions and on solving the coupled local-mode equations to obtain a quantitative description of the intermodal energy exchange.

The $\mathrm{CO}_{2}$ laser irradiation technique could also be used to write a LPFG in a conventional or photonic crystal polarization-maintaining (PM) fibers [92]. Such a LPFG has two clean polarization-splitting rejection bands. The writing efficiencies of gratings in the two types of PM fibers depend strongly on the fiber orientation, with the highest efficiency obtained when the irradiation direction is along the slow axis of the fiber [92]. Such orientation dependence is much stronger for a conventional PM fiber than for a photonic crystal PM fiber and is attributed to the relaxation of mechanical stress in the stress-applying parts of the fiber.

\section{To write LPFGs in air-core PBFs}

As discussed above, a large number of gratings have been demonstrated in different types of PCFs by the use of various fabrication techniques [34, 41, 43, 85, 93]. All of these gratings, however, were written in index-guiding PCFs, instead of bandgap-guiding fibers. Recently, PBF- 
based gratings were also written in a new kind of bandgap-guiding fibers such as fluid-filled PBFs [50, 94-97] and all-solid PBFs [98, 99]. However, PBF-based gratings have not been reported in air-core PBFs until recent success in writing a high-quality LPFG in an air-core PBF [26].

Since almost $100 \%$ of the light propagates in the air holes of an air-core PBF and not in the glass [84], PBF-based gratings offer a number of unique features including: high dispersion, low nonlinearity, reduced environmental sensitivity, unusual mode coupling, and new possibilities for long-distance light-matter interactions (by incorporating additional materials into the air-holes). Bandgap-based grating in air-core PBFs, therefore, represent an important platform technology with manifest applications in areas such as communications, fiber lasers and sensing. Periodic index modulations are usually required to realize mode coupling in in-fiber gratings. Although this presents no difficulties in conventional glass fibers [16, 21], solid-core PCFs [12, 20, 25], and solid-core PBFs [50, 95-99], it is very difficult, even impossible, to directly induce index modulations in an air-core PBF due to the air core structure, thereby seriously obstructing the development of PBF-based gratings over the past decade.

Wang et al. reported what is believed to be the first example of gratings written in an air-core PBF by the use of a focused $\mathrm{CO}_{2}$ laser beam to periodically deform/perturb air holes along the fiber axis in 2008 [26], as shown in Fig. 7. This reveals that it is experimentally possible to write a grating in an air-core PBF. Both the excellent stability of $\mathrm{CO}_{2}$ laser power and the good repeatability of optical scanning are very critical to writing a high-quality grating in an air-core PBF. An experimental setup being similar to that in Fig. 2 was used to write a LPFG in an aircore PBF (Crystal-Fiber's HC-1500-02). Compared with the fabrication parameters for writing a grating in a solid-core PCF [24, 25], an lower average laser power of about $0.2 \mathrm{~W}$ and shorter total time of laser irradiation are used to write a LPFG in an air-core PBF [26]. The focused $\mathrm{CO}_{2}$ beam scans periodically the PBF with a line speed of scanning of $2.9 \mathrm{~mm} / \mathrm{s}$, causing the ablation of glass on the fiber surface and the partial or complete collapse of air holes in the cladding due to the $\mathrm{CO}_{2}$-laser-induced local high temperature, as shown in Fig. 7. The outer rings of air holes in the cladding, facing to the $\mathrm{CO}_{2}$ laser irradiation, were largely deformed; however, little or no deformation were observed in the innermost ring of air-holes and in the air core. As a result, periodic index modulations are achieved along the fiber axis due to the photoelastic effect, thus creating a novel LPFG in the air-core PBF. For the LPFG written in air-core PBF, periodic perturbations of the waveguide (geometric) structure could be the dominant factor that causes resonant mode coupling, although the stress-relaxation-induced index variation may also contribute a little. 

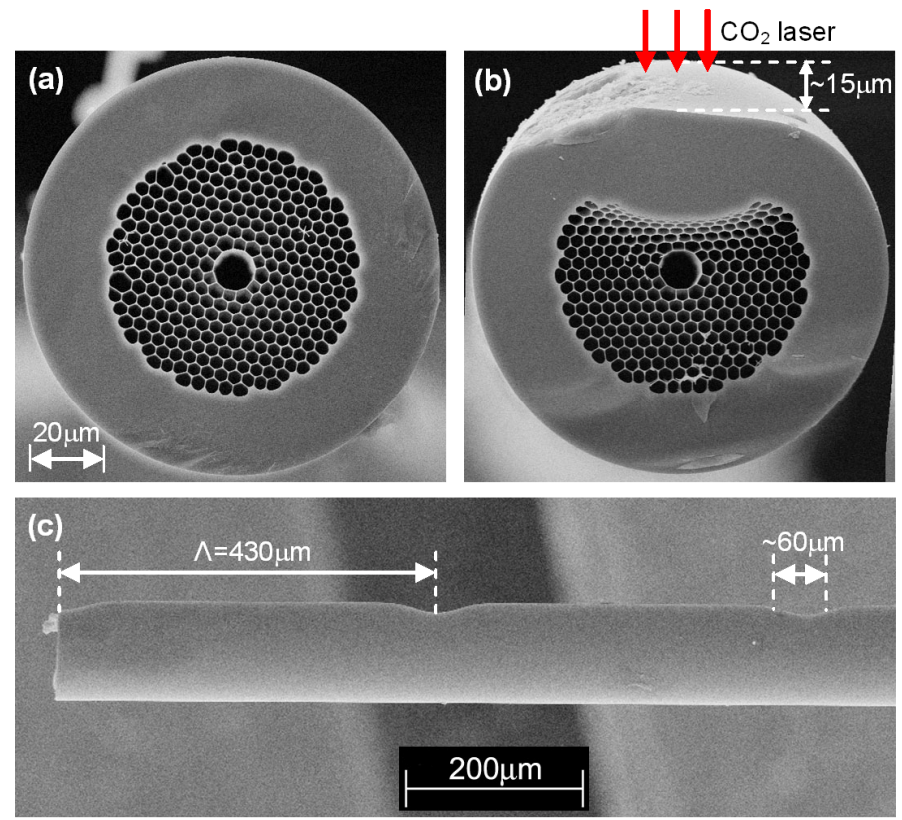

Fig. 7 Cross-section image of an air-core PBF (a) before and (b) after $\mathrm{CO}_{2}$ laser irradiating, (c) side image of a LPFG written in the air-core PBF, where about two periods of the LPFG are illustrated [26].

Normal LPFGs written in the index-guiding fibers have a positive relationship between resonant wavelength and grating pitch $[5,6,8,9]$. In contrast, the LPFGs written in the bandgapguiding air-core PBF have distinct phase matching condition as function of wavelength. As shown in Fig. 8, the resonant wavelengths of the LPFGs written in an air-core PBF decrease with the increase of grating pitch, which is opposite to the LPFGs written in the index-guiding fibers $[5,6]$. Moreover, this PBF-based LPFG has unique optical properties such as very large PDL, large strain sensitivity, and very small sensitivity or insensitivity to temperature, bend and external refractive index, as shown in Fig. 4 in Ref. [26]. Further investigations are being done to well understand resonant mode coupling and unique optical properties in the gratings written in air-core PBFs.

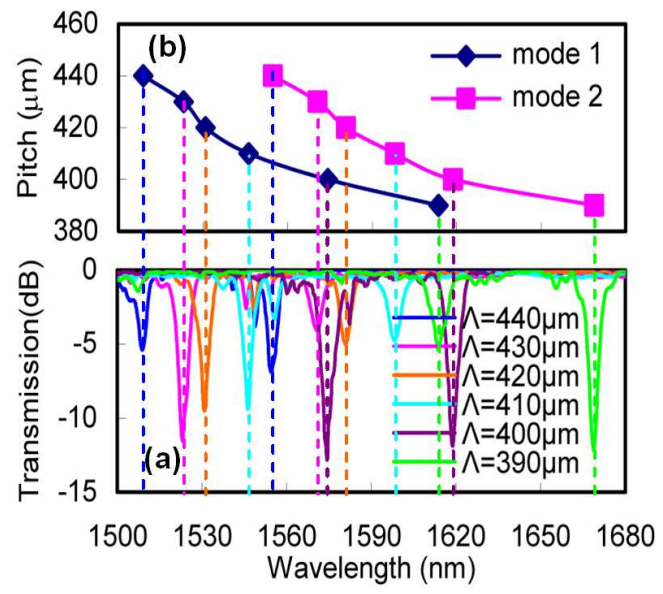


Fig. 8 (a) Transmission spectra of six LPFGs, with different grating pitches, written in an air-core PBF, (b) the relationship between the pitch of each LPFG and the corresponding research wavelength, where two attenuation dips for each LPFG are observed from 1500 to $1680 \mathrm{~nm}$, indicating that the fundamental mode is coupled to two different higher order modes [26].

\section{REFRACTIVE INDEX MODULATIONS}

Possible mechanisms for refractive index modulation in the $\mathrm{CO}_{2}$-laser-induced LPFGs could be attributed to residual stress relaxation [73-75, 100], glass densification [71, 72, 101, 102], and/or physical deformation, depending on the types of the employed fibers and on the practical fabrication techniques. A few methods have been demonstrated to measure the refractive index modulation in the $\mathrm{CO}_{2}$-laser-induced LPFGs [100, 103].

\section{A. Residual stress relaxation}

Residual stress relaxation is found to be the main mechanism for the refractive-index change in the $\mathrm{CO}_{2}$-laser-induced LPFGs written in optical fibers drawn at high drawing forces [73-75, 100]. Residual stress is formed in optical fibers during the drawing process, resulting mainly from a superposition of thermal stress caused by a difference in thermal expansion coefficients between core and cladding and mechanical stress caused by a difference in the viscoelastic properties of the two regions $[74,75,104]$. Such residual stress can change refractive index in the fibers through the stress-optic effect and thus affect the optical properties of the fibers. Mechanical stress in a $\mathrm{CO}_{2}$-laser-induced LPFG written in a Ge-B-codoped fiber can be fully relaxed by $\mathrm{CO}_{2}$ laser irradiation. Consequently, only thermal stress remains in the fiber core due to a mismatch of the thermal expansion coefficients of the fiber core and cladding. Residual stress relaxation usually results in a decrease of refractive index in the fibers. And the efficiency of refractive-index decrease depends strongly on the types of fiber and can be enhanced linearly with the drawing force during the drawing process of the fiber [73-75]. For example, the refractive-index change, resulting from residual stress relaxation, in a Ge-B-codoped fiber drawn at $0.53,1.38,2.50$, and $3.43 \mathrm{~N}$ was measured to be $-3.6 \times 10^{-5},-8.0 \times 10^{-5},-1.7 \times 10^{-4}$, and $-2.1 \times$ $10^{-4}$, respectively [75]. Another experiment shows that residual stress relaxation results in a larger refractive index change of $-7.2 \times 10^{-4}$ in a Corning SMF-28e fiber [100].

\section{B. Glass structure changes}

The changes of glass structure (glass volume increase and glass densification) play the dominant mechanisms in the $\mathrm{CO}_{2}$-laser-induced LPFGs written in a commercial boron-doped single-mode fiber $[71,72,101,102]$. For an unannealed fiber or a fiber annealed at a temperature lower than about $380^{\circ} \mathrm{C}$, glass densification, resulting in an increase in the refractive index, plays the dominant role [72]. For a fiber annealed at a higher temperature than about $400^{\circ} \mathrm{C}$, however, glass volume increase, resulting in a decrease in the refractive index, becomes more important [72]. On the other hand, residual stress relaxation in the fiber core, which is the dominant mechanism in a conventional Ge-doped or Ge-B-codoped fiber, plays only a minor role in the boron-doped fiber that has a core with a small residual stress and a low fictive temperature.

For the $\mathrm{CO}_{2}$-laser-induces LPFGs in the Ge-doped or Ge-B-codoped fibers, e.g. Corning SMF-28 fiber, with large residual stress, the resonance wavelength shifts towards the shorter wavelength with the increase of the laser exposure dose due to the negative index modulation resulting from residual stress relaxation [73-75, 100]. For the $\mathrm{CO}_{2}$-laser-induced LPFGs in the boron-doped fibers with small residual stress, on the contrary, the resonance wavelength shifts towards the longer wavelength with the increase of the laser exposure dose due to the positive index modulation resulting from glass densification $[71,72,101,102]$. 


\section{Physical deformation}

Physical deformation also is one of main fabrication mechanisms of the $\mathrm{CO}_{2}$-laser-induced LPFGs. During $\mathrm{CO}_{2}$ laser irradiation, the fiber usually elongates or tapers based on the so-called "self-regulating" mechanism [105], resulting from constant axial tension and the $\mathrm{CO}_{2}$-laserinduced local high temperature in the fiber. Thus the fiber diameter decreases and eventually reaches a critical point at which the fiber elongation stops because no sufficient energy is absorbed to keep the softening temperature. Such physical deformation induces a change of effective refractive index in the fiber, and thus LPFGs are created in the periodically taped optical fibers [19, 68-70]. Moreover, the $\mathrm{CO}_{2}$-laser-induced high temperature in the fiber causes, not only the fiber elongation and the diameter decrease, but also the ablation of glass on the fiber surface and the partial or complete collapses of air holes in the PCFs. As a result, different types of LPFGs are written in conventional glass fibers in which periodic grooves/microbends are created on the fiber surface $[19,23,68-70]$, and in microstructured optical fibers, such as solid-core PCFs $[20,24,25,27]$ and air-core PBF [26], in which air holes are partially or completely collapsed.

Theoretical and experimental investigations show that the microdeformation-induced LPFGs in pure-silica PCFs have discrete attenuation peaks whose spectral positions are correlated to the beat length between the fundamental mode and the first higher-order mode [106]. Thus, simple description of the modal properties based on the perfectly uniform fiber structure may explain the mode-coupling properties of the microdeformation-induced LPFGs in pure-silica PCFs [106].

\section{ASYMMETRICAL MODE COUPLING}

Asymmetrical mode coupling is one of the most distinctive features in the $\mathrm{CO}_{2}$-laser-induced LPFGs, resulting in unique optical properties those have a large number of promising sensing and communication applications [21, 23], as discussed below in Sections VI and VII. As shown in Fig. 9(a), the laser energy is strongly absorbed on the incident side of the fiber while the $\mathrm{CO}_{2}$ laser light $(\lambda=10.6 \mu \mathrm{m})$ illuminates on the optical fiber [107]. The non-uniform absorption results in an asymmetrical refractive index profile within the cross-section of the $\mathrm{CO}_{2}$-laserinduced LPFGs. In other words, a larger refractive index change is induced in the incident side of the fiber than in the opposite side. Consequently, as shown in Fig. 9(b), asymmetrical mode coupling occurs in the $\mathrm{CO}_{2}$-laser-induced LPFGs [17, 108-111] so that a higher PDL usually are observed in the gratings $[25,63,110]$. Such asymmetrical mode coupling also results that the responses of the $\mathrm{CO}_{2}$-laser-induced LPFGs to the applied bending [21, 107, 112-114], twisting [115-117] and transverse-loading [118-120] depend strongly on the fiber orientations, which is distinct from the gratings written by the UV exposure technique [7, 12-14]. Moreover, the asymmetry in the stress distribution of the cladding is found to be much larger than that in the core of the $\mathrm{CO}_{2}$-laser-induced LPFG [110]. So the polarization-dependent transmission characteristics of the LPFG are affected mostly by the asymmetric stress distribution in the cladding region rather than the core region. 


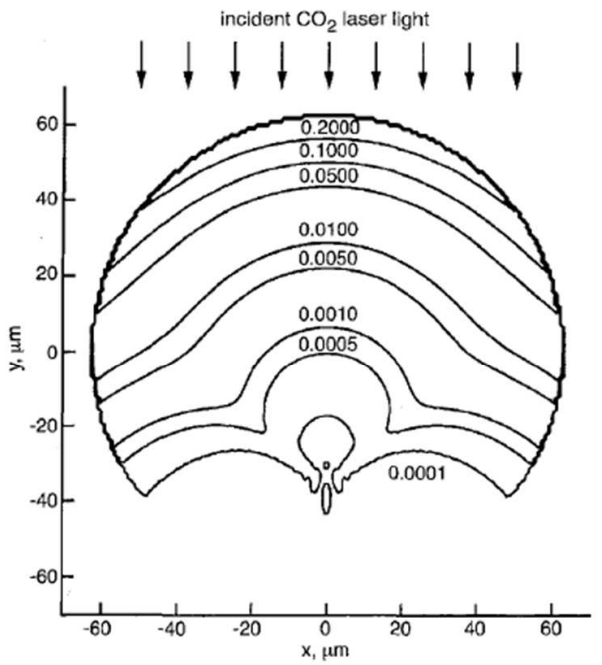

(a)

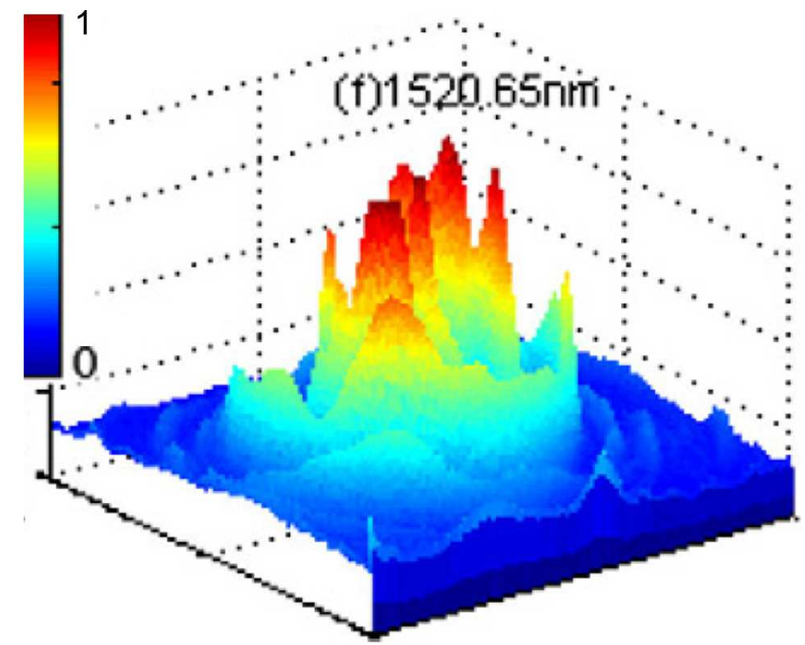

(b)

Fig. 9 (a) Calculated intensities (relative to unity incident intensity) within the cross-section of optical fiber during the single-side irradiation of $\mathrm{CO}_{2}$ laser light [107]; (b) Asymmetrical mode coupling at the resonant wavelength in the $\mathrm{CO}_{2}$ laser-induced LPFG [108].

To solve the problem of asymmetrical mode coupling in LPFGs written by one-sided exposure of $\mathrm{a} \mathrm{CO}_{2}$ laser beam, various methods based on symmetric exposure of the laser beam were demonstrated to achieve axially symmetric LPFG by rotating the fiber during exposure [121], by focusing a ring-shaped $\mathrm{CO}_{2}$ laser beam axially on the fiber with a concave mirror [121], and by placing a special reflector behind the fiber [122]. The achieved LPFGs with an axially symmetric refractive index profile exhibit clean spectra, very low insertion loss $(<0.1 \mathrm{~dB})$ and a low PDL of $0.21 \mathrm{~dB}$ [121] or less than $0.12 \mathrm{~dB}$ [122]. These values are much lower than the reported measurements of standard $\mathrm{CO}_{2}$-laser-induced gratings (whose PDL is typically $1 \mathrm{~dB}$ ) $[17,21,110]$ and are close to those of UV-written gratings [5, 6]. Zhu et al. reported a multi-edge exposure method for decreasing the polarization dependence of the $\mathrm{CO}_{2}$-laser-induced LPFG and demonstrated a triple-edge-written LPFG with a low PDL of $0.22 \mathrm{~dB}$ [66].

\section{ENHANCEMENT IN THE EFFICIENCY OF GRATING FABRICATIONS}

The efficiency of grating fabrications employing a $\mathrm{CO}_{2}$ laser can be significantly enhanced by pretreatment techniques, such as hydrogen loading and applying prestrain, and by post-treatment techniques such as apply tensile strain and changing temperature.

\section{A. Pretrement techniques: hydrogen loading and applying prestrain}

\section{Hydrogen loading}

As well-known, the use of hydrogen loading can enhance the photosensitivity of the Gedoped fibers to UV exposure [5, 123]. Hydrogen loading are also found to enhance the writing sensitivity of the $\mathrm{CO}_{2}$-laser-induced LPFGs [16, 124]. As shown in Fig. 10, the spectrum characteristics of the $\mathrm{CO}_{2}$-laser-induced LPFG in the $\mathrm{H}_{2}$-loaded fiber are dramatically different from those obtained in the untreated fiber [124]. The spectrum of the grating written in an $\mathrm{H}_{2^{-}}$ loaded fiber shows a clear coupling to the symmetric modes. In contrast, the coupling peaks for the grating written in the untreated fiber are much broader and the overall background losses are 
higher, especially in the $1550 \mathrm{~nm}$ wavelength range. The poor quality of the LPFG written in the non- $\mathrm{H}_{2}$-loaded fiber results from the large laser exposure power required to create such a grating [124].

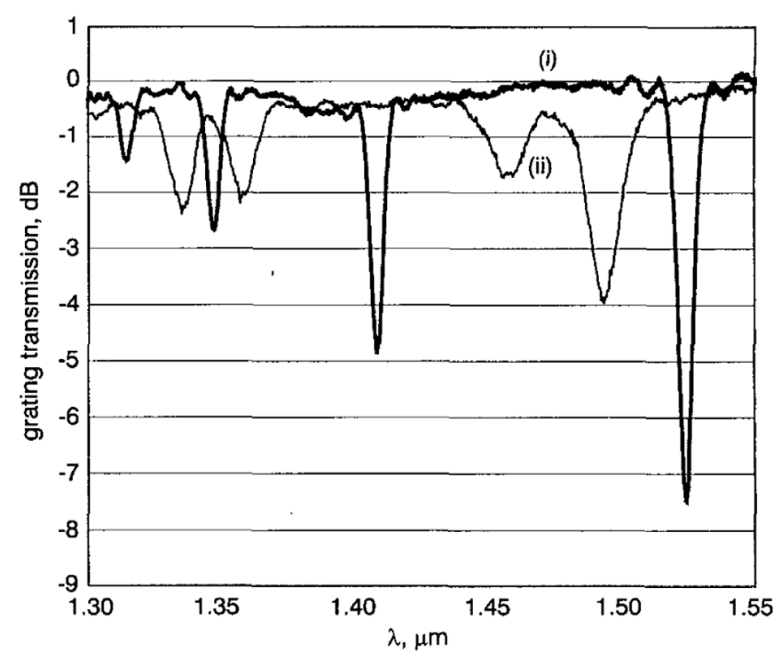

Fig. 10 Transmission spectra of the $\mathrm{CO}_{2}$-laser-induced LPFGs in $\mathrm{H}_{2}$-loaded and untreated standard fiber (grating pitch: $450 \mathrm{~mm}$ ), (i) $\mathrm{H}_{2}$-loaded fiber with an exposure power of $0.5 \mathrm{~W}$, (ii) untreated standard fiber with an exposure power of $2.3 \mathrm{~W}[124]$.

\section{Applying prestrain}

Viscoelastic strains can be frozen into the fiber during drawing an optical fiber, or by cooling down a drawn fiber from its fictive temperature under tension [125-128]. Such a frozen-in viscoelasticity has a significant impact on the refractive index profile of optical fibers. Hence it is possible to change frozen-in viscoelasticity to modulate refractive index in the fiber via heat treatment of a post-draw fiber under tension. Numerous experiments thus reveal that the efficiency of grating fabrication employing a $\mathrm{CO}_{2}$ laser can be enhanced by means of applying a tensile strain to the employed fiber during $\mathrm{CO}_{2}$ laser irradiation [21, 23, 29, 129-131], which may be due to the frozen-in viscoelasticity in the fiber. For example, as shown in Figs. 2 and 3, one of the fiber ends was tensed by a small weight to provide an external tensile strain in the fiber in advance, enhancing the efficiency of the grating fabrication [21, 23]. Liu et al. investigated experimentally the effect of the applied tension on the writing efficiency [29, 129-131]. As shown in Fig. 11, the threshold energy density of $\mathrm{CO}_{2}$ laser irradiation required to write a grating decreases dramatically with an increase in the applied tension [29, 129]. The significant enhancement in the writing efficiency with an applied tension is attributed to the mechanism of frozen-in viscoelasticity in the fiber at the spots of the $\mathrm{CO}_{2}$ laser irradiation [129]. To write a grating in an unstressed fiber, a sufficiently high temperature in the core has to be required to relax the residual stress in the core, which demands a high dose of $\mathrm{CO}_{2}$ laser irradiation because the temperature inside the irradiated fiber decreases rapidly from the surface towards the core $[105,107]$. To write a grating in a strongly stressed fiber, however, only a sufficiently high temperature on the fiber surface is required to induce viscoelastic strains in the exposed cladding, which can be achieved with a relatively low energy density of $\mathrm{CO}_{2}$ laser $[29,129]$. 


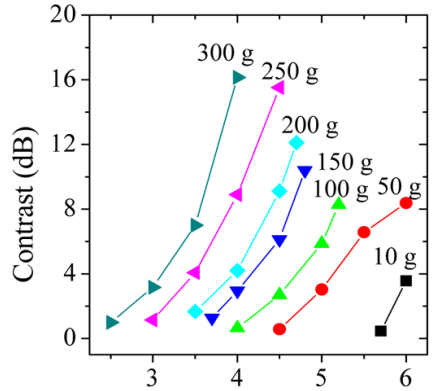

(a) Energy Density $\left(\mathrm{J} / \mathrm{mm}^{2}\right)$

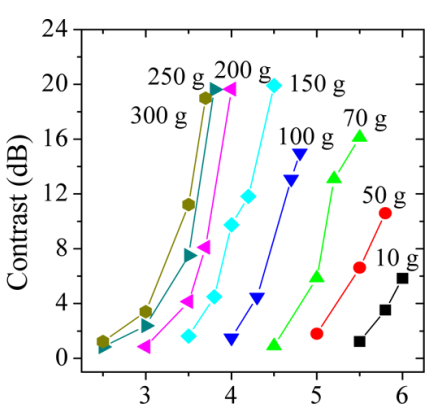

(b) Energy Density $\left(\mathrm{J} / \mathrm{mm}^{2}\right)$

Fig. 11 Dependence of the grating contrast on the $\mathrm{CO}_{2}$ laser energy density for LPFGs written in (a) SMF-130V and (b) SMF-28e fibers subject to different applied weights using one scanning cycle of $\mathrm{CO}_{2}$ laser irradiation $[29,129]$.

However, Zhang et al. recently discovered that the applied tension during the writing process does not always increase the writing efficiency [132]. For example, during writing a LPFG in a commercial Ge-B-codoped fiber with $\mathrm{CO}_{2}$ laser irradiation, without applying tension to the fiber, a low $\mathrm{CO}_{2}$ laser dosage is sufficient to produce clean strong rejection bands for axially symmetric cladding modes [132]. On the contrary, with applying a sufficient tension, e.g. a 200-g applied tension, to the fiber, the rejection bands for axially symmetric cladding modes is suppressed due to the counteracting effects of glass densification and frozen-in strain in the core, while new rejection bands for nonaxially symmetric cladding modes are generated [132].

\section{B. Post-treatment techniques: applying tensile strain and changing temperature}

\section{Applying tensile strain}

Experimental investigations show that mode coupling in the $\mathrm{CO}_{2}$-laser-indcued LPFGs [89, 133], especially the $\mathrm{CO}_{2}$-laser-carved LPFGs with periodic grooves [23, 63], can be greatly enhanced by applying an suitable external stretching force to the LPFGs after writing gratings. For example, as shown in Fig. 12(a)), the peak transmission attenuation at the resonant wavelength of the $\mathrm{CO}_{2}$-laser-carved LPFG with periodic grooves was increased from - 28.422 to $54.335 \mathrm{~dB}$ when a tensile strain of about $355.0 \mu \varepsilon$ was applied to the grating [63]. Such enhancement in mode coupling is attributed to the stretch-induced periodic microbends, as discussed below in Section VI(A). It can also be seen from Fig. 12(a) that the peak transmission attenuation will reduced if a larger tensile strain, e.g. $525.5 \mu \varepsilon$, is applied to the grating due to the over-coupling between the fundamental and cladding modes. Thus, this provides an alternative post-treatment technique for enhancing the efficiency of grating fabrication to achieve a desired attenuation spectrum. Moreover, as shown in Fig. 12(b), the polarization dependence of the $\mathrm{CO}_{2}-$ laser-induced LPFG is also enhanced or reduced with an increase of the tensile strain. The maximum PDL was increased to $27.2 \mathrm{~dB}$ when a tensile strain about $355.0 \mu \varepsilon$ was applied to the grating. Hence such a post-treatment technique employing a tensile strain can be used to develop an in-fiber polarizer, as discussed below in Section VII(C). 


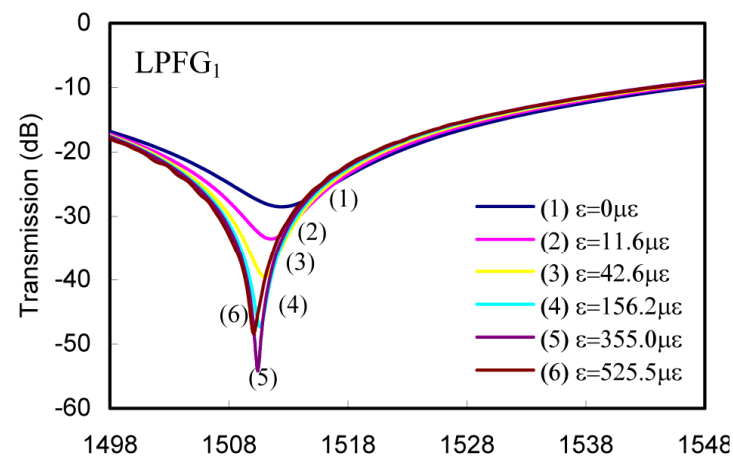

(a) Wavelength $(\mathrm{nm})$

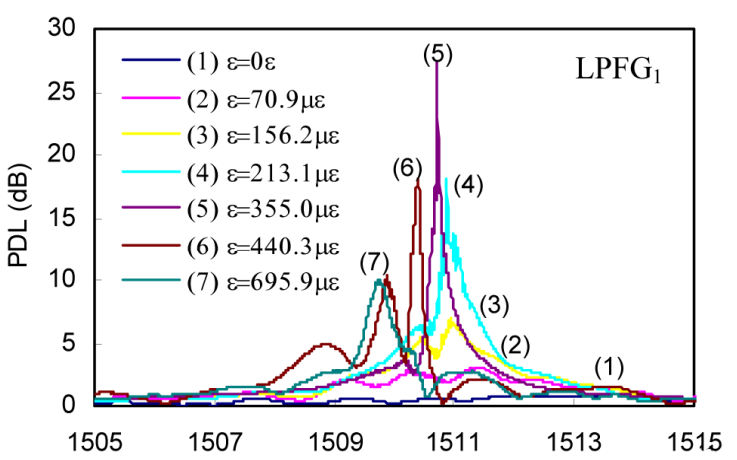

(b) Wavelength $(\mathrm{nm})$

Fig. 12 Evolutions of (a) transmission spectrum and (b) polarization dependence in the $\mathrm{CO}_{2}$-laser-carved LPFG with period grooves while increasing the applied tensile strain [63].

\section{Changing temperature}

Another post-treatment technique has been demonstrated to enhance the efficiency of grating fabrication by means of changing temperature. As shown in Fig. 13 (a), the peak transmission attenuation at the resonant wavelength of the $\mathrm{CO}_{2}$-laser-carved LPFG with periodic grooves was increased from -25.18 to $-35.20 \mathrm{~dB}$ when the temperature of the grating rose to $100{ }^{\circ} \mathrm{C}$, resulting from additional refractive index perturbation induced by the thermal strain in the asymmetric LPFG [134]. Thus, this provides another alternative post-treatment technique for enhancing the efficiency of grating fabrication to achieve a desired attenuation spectrum. This unique temperature characteristic in the $\mathrm{CO}_{2}$-laser-carved $\mathrm{LPFG}$ can be used to develop a practical temperature sensor based on intensity modulation, as discussed below in Section VI(A). Moreover, as shown in Fig. 13(b), the polarization dependence of the $\mathrm{CO}_{2}$-laser-carved LPFG was also enhanced with temperature rise, which could find potential sensing or communication applications base on polarization dependence modulation.
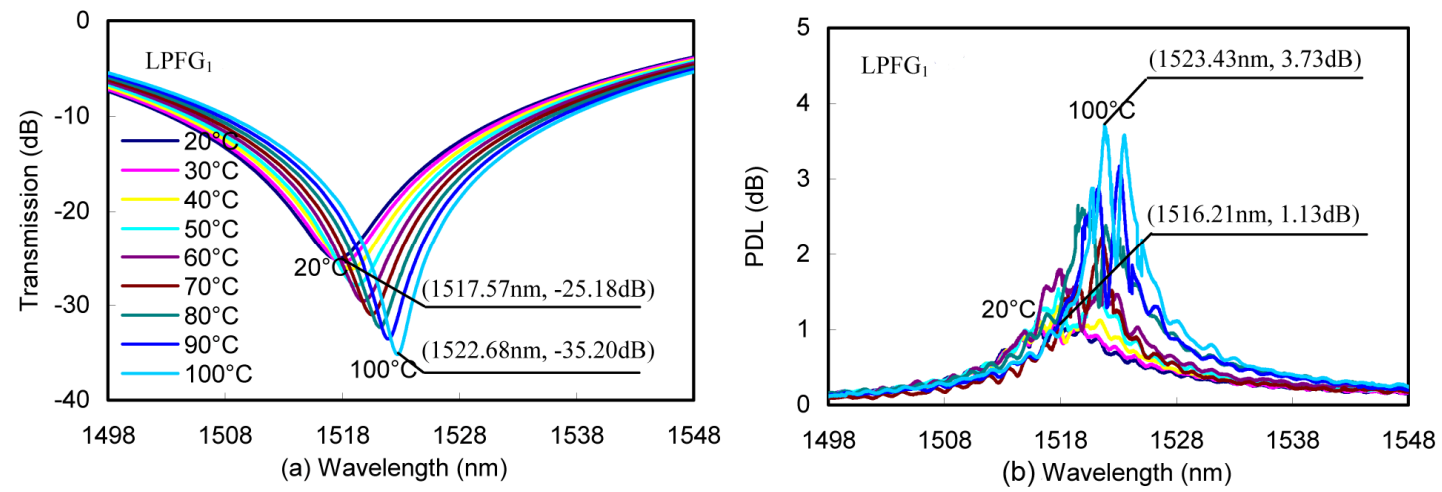

Fig. 13 (a) Evolutions of (a) transmission spectra and (b) polarization dependence in the $\mathrm{CO}_{2}$-laser-carved LPFG with periodic grooves while the temperature is increased from $20^{\circ} \mathrm{C}$ to $100{ }^{\circ} \mathrm{C}$ in steps of $10^{\circ} \mathrm{C}$ [134]. 


\section{SENSING APPLICATIONS}

The $\mathrm{CO}_{2}$-laser-induced LPFGs have found many promising sensing applications for temperature, strain, bend, torsion, pressure, and biochemical sensors because of the sensitivities of resonance wavelength and attenuation amplitude to these measured parameters $[4,7,14,15$, $21,135]$.

\section{A. Temperature sensors}

Transmission spectra of the $\mathrm{CO}_{2}$-laser-induced LPFGs shift linearly with the change of temperature and are exceptionally stable even when subjected to a very high temperatures of up to $1200^{\circ} \mathrm{C}[18,89]$. Therefore the $\mathrm{CO}_{2}$-laser-induced LPFGs are excellent temperature sensing elements, especially high temperature sensors. In contrast, the sensors employing a UV-laserinduced grating usually have to work under a temperature of about $300^{\circ} \mathrm{C}$. Temperature sensitivities of resonance wavelength of LPFGs depend strongly on the types of the fibers employed and fabrication techniques [7]. For example, temperature sensitivities of 58, 10.9, and $2.9 \mathrm{pm} /{ }^{\circ} \mathrm{C}$ were demonstrated in the $\mathrm{CO}_{2}$-laser-induced LPFGs written in a conventional glass fiber [21], a solid-core PCF [89], and an air-core PBF [26], respectively. Especially, the resonance wavelength of the LPFG written in a solid-core PCF has a very low strain sensitivity of $-0.192 \mathrm{pm} / \mu \varepsilon[89]$, thus solving the cross-sensitivity problem between temperature and strain in sensing applications.

The coupling from the fundamental mode to the cladding modes in normal LPFGs is hardly affected by the change of temperature except for the shift of transmission spectrum. So the temperature sensors based on this types of LPFGs usually have to measure the shift of resonant wavelength [7, 21, 136, 137], which needs expensive equipments, e.g. an optical spectrum analyzer, and thus is not suitable for practical applications. As shown in Fig. 13, the mode coupling in the $\mathrm{CO}_{2}$-laser-induced LPFG with periodic grooves can be enhanced by increasing the ambient temperature, and the PDL in the LPFG is also changed [134, 138]. Hence, such a LPFG with periodic grooves is a potential temperature sensor based on the intensity modulation and/or on the PDL modulation. For example, as shown in Fig. 14, a practical temperature sensing system based on intensity modulation was developed by the use of a $\mathrm{CO}_{2}$-laser-induced LPFG with periodic grooves as a sensing element [138], in which two FBGs were employed to select two different single wavelengths. Such a temperature sensing system exhibits a number of advantages such as convenient intensity measurement, double temperature sensitivity, high resolution of $0.1{ }^{\circ} \mathrm{C}$, and simple configuration.

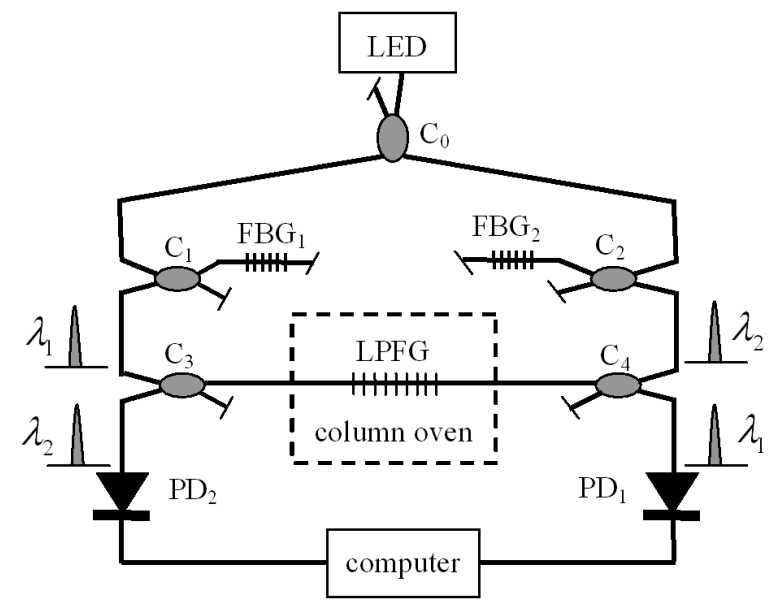


Fig. 14 Schematic diagram of the temperature sensor system based on intensity modulation [138].

\section{B. Strain sensors}

The $\mathrm{CO}_{2}$-laser-induced LPFGs with physical deformations exhibit unique optical properties while a tensile strain is applied [23, 24, 63, 69, 70, 133], thus being excellent strain sensing elements. As shown in Fig. 15, periodic microbends will be induced while a $\mathrm{CO}_{2}$-laser-induced LPFG with asymmetric grooves is stretched [23, 24, 63]. Such stretch-induced microbends effectively enhance refractive index modulation in the gratings. As a result, such a LPFG have an extremely high strain sensitivity of $-102.89 \mathrm{~nm} / \mu \varepsilon$ [23, 63], which is two orders of magnitude higher than that of other $\mathrm{CO}_{2}$-laser-induced LPFGs without physics deformations in the same type of fibers [21].

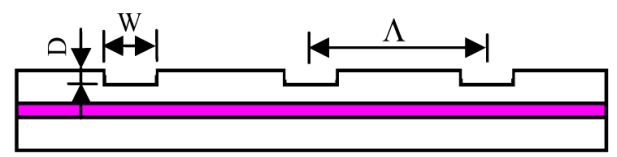

(a)

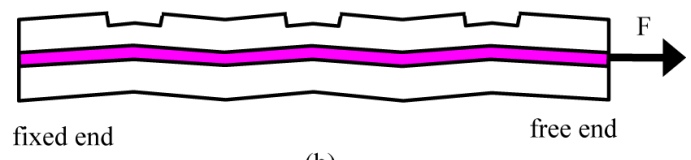

(b)

Fig. 15 Schematic diagram of the $\mathrm{CO}_{2}$-laser-carved $\mathrm{LPFG}$ with asymmetric grooves (a) before and (b) after a stretching force is applied to the grating [23].

A LPFG strain sensor with a high strain sensitivity of $-7.6 \mathrm{pm} / \mu \varepsilon$ and a very low temperature sensitivity of $3.91 \mathrm{pm} /{ }^{\circ} \mathrm{C}$ has been developed by the use of focused $\mathrm{CO}_{2}$ laser beam to carve periodic grooves on the large mode area PCF [24]. Such a strain sensor can effectively reduce the cross-sensitivity between strain and temperature, and the temperature-induced strain error obtained is only $0.5 \mu \varepsilon /{ }^{\circ} \mathrm{C}$ without temperature compensation. Another strain sensor based on a $\mathrm{CO}_{2}$-laser-induced LPFG pair in a PCF exhibits a high stain sensitivity of about $-3 \mathrm{pm} / \mu \varepsilon$ and a low temperature sensitivity of about $4.6 \mathrm{pm} /{ }^{\circ} \mathrm{C}[90]$. Theoretical analysis reveals that a simple, low-cost LPG sensor with approximately zero temperature sensitivity but large strain sensitivity could be realized by selecting an appropriate grating period [139]. Moreover, temperatureindependent strain sensors were demonstrated by measuring the separation change between the two spit peaks of LPFGs written in the twisted optical fibers with a $\mathrm{CO}_{2}$ laser and exhibited a high strain sensitivity of about $106.7 \mathrm{pm} / \mu \varepsilon$ [140, 141].

\section{Bend sensors}

As discussed above in Section IV, the single-side irradiation of the $\mathrm{CO}_{2}$ laser beam results in an asymmetrical index profile within the cross-section of the achieved gratings. As a result, distinct bend-sensitivity of resonant wavelength are observed while a $\mathrm{CO}_{2}$-laser-induced LPFG is bent to different fiber orientations [107, 113, 114], as shown in Fig. 16. In other words, the bending responses of the $\mathrm{CO}_{2}$-laser-induced LPFGs depend strongly on the bending direction, which is distinct from that of the UV-laser-written LPFGs in which nearly symmetrical index modulations are limited in the fiber core. As shown in Fig. 17, a promising bend-sensing system based on the axial rotation dependence of the bending response in the $\mathrm{CO}_{2}$-laser-induced LPFGs has been developed to measure directly the applied curvature of the engineering structures and to determine simultaneously the bending direction [114]. This bend-sensing system consists of one 
UV-laser-induced LPFG and two $\mathrm{CO}_{2}$-laser-induced LPFGs. The curvature of the engineering structure is measured by the UV-laser-induced LPFG whose bend-sensitivity is independent on the bending directions, and the bending direction is determined by the two $\mathrm{CO}_{2}$-laser-induced LPFGs whose bend-sensitivities depend strongly on the bending directions. Similar orientation dependence of the bending response also was observed in FBGs written in the Ge-doped microstructured optical fibers [87].

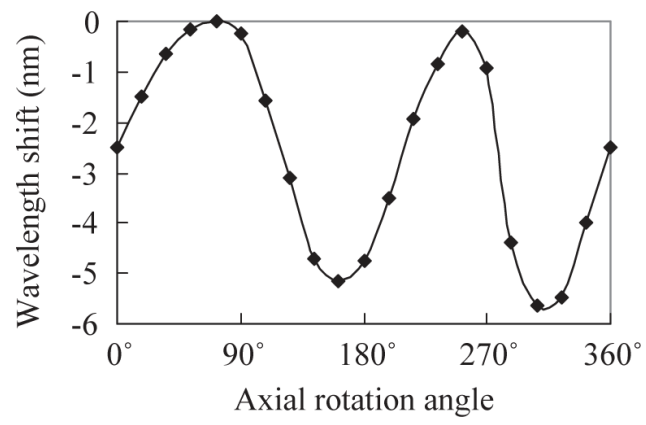

Fig.16 The shift of resonant wavelength while the $\mathrm{CO}_{2}$-laser-induced LPFG is bent to different fiber orientations [113].

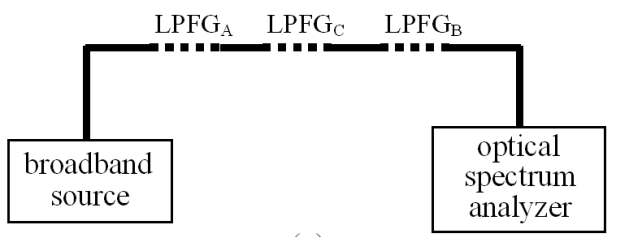

(a)

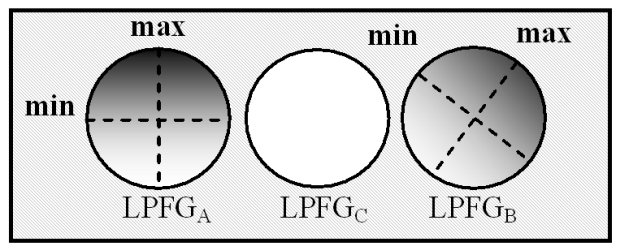

(b)

Fig. 17 Schematic diagram of LPFGs sensor that can not only measure curvature but also determine bending direction, (a) sensor scheme, (b) cross section of three LPFGs [114]

It is interesting to see from Fig. 16 that the resonant wavelength is insensitive to the curvature change or has a very low bend-sensitivity while the $\mathrm{CO}_{2}$-laser-induced LPFG is bent toward special fiber orientations, e.g. about $90^{\circ}$ and about $270^{\circ}$ orientations. Thus such a LPFG can be used to develop a bend-insensitive sensor to solve the problem of cross-sensitivity between bend and other measurands, such as temperature, strain or refractive index, which is an unsolved problem for normal grating-based sensors in practice [113]. On the other hand, the resonant wavelength shift linearly while the $\mathrm{CO}_{2}$-laser-induced LPFG is bent toward other fiber orientations, as shown in Fig. 3 in Ref. [114] and Fig. 7 in Ref [142]. Hence such a grating can also be used to measure directly the applied curvature of engineering structures. 


\section{Torsion sensors}

All-fiber torsion sensors have been demonstrated by the use of a corrugated LPFG [54, 143]. These LPFG torsion sensors, however, cannot determine the twisting directions, i.e. whether clockwise or anticlockwise. It is interesting to see from Fig. 18(a) that the resonant wavelength shifts linearly toward the longer wavelength while a $\mathrm{CO}_{2}$-laser-induced LPFG is twisted clockwise, whereas it shifts linearly toward the shorter wavelength while the grating is twisted anticlockwise [115, 117]. Hence such a $\mathrm{CO}_{2}$-laser-induced LPFG is an excellent in-fiber torsion sensing element that can, not only measure directly the applied twisting rate, but also determine simultaneously the twisting direction [115]. Furthermore, providing the twisted fiber including a $\mathrm{CO}_{2}$-laser-induced LPFG is much longer than the grating, as shown in Fig. 18(b), the resonant wavelength shifts wavelike toward the longer and shorter wavelength while the LPFG is twisted clockwise and anticlockwise, respectively [116, 117]. Such unique torsion characteristics of the $\mathrm{CO}_{2}$-laser-induced LPFGs owe to the twist-induced right- and left-rotatory elliptical birefringence, resulting from asymmetric refractive index distribution within the cross section of the gratings.

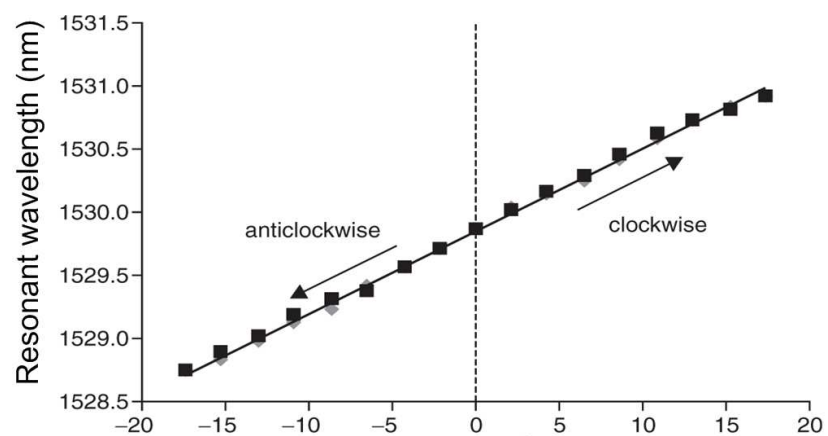

(a) Twist rate $(\mathrm{rad} / \mathrm{m})$

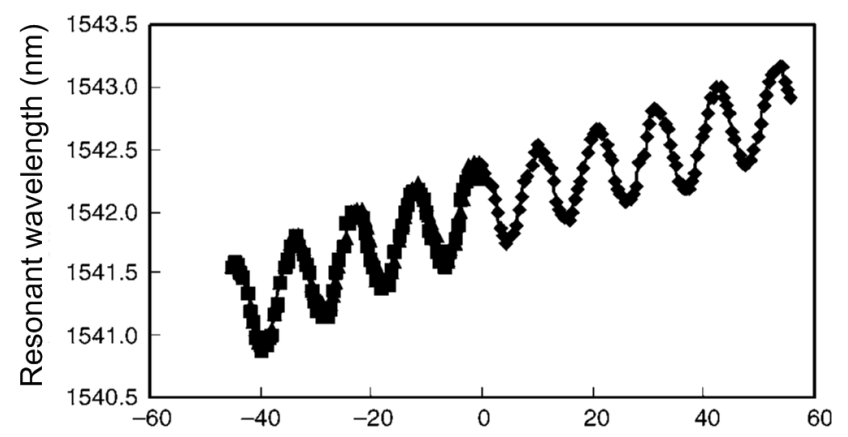

(b) Twist rate $(\mathrm{rad} / \mathrm{m})$

Fig.18 (a) Resonant wavelength change while a $\mathrm{CO}_{2}$-laser-induced LPFG is twisted clockwise or anticlockwise [115]; (b) The response of resonant wavelength to the torsion providing the twisted fiber including a $\mathrm{CO}_{2}$-laserinduced LPFG is much longer than the grating [116].

Moreover, Rao et al. reported that the high order resonant wavelengths of the $\mathrm{CO}_{2}$-laserinduced ultra-long period fiber gratings have higher torsion sensitivities, which is several times higher than that of the normal LPFG [80]. An intensity-type demodulation approach used to realize real-time torsion measurement has been demonstrated based on the edge filtering effect of ultra-long period fiber gratings [80]. The helical LPFG written by $\mathrm{CO}_{2}$ laser irradiation can also be used as an optical torsion sensor because its attenuation peak shifts with codirectional or contradirectional torsion to the helix [67]. In addition, the rejection band of a LPFG written in a 
heavily twisted single-mode fiber by a $\mathrm{CO}_{2}$ laser can split into two bands when the twist applied to the fiber is removed after the writing of the grating [144]. Such a grating could find applications as a temperature-insensitive torsion sensor.

\section{E. Pressure sensors}

Resonant wavelength of optical fiber gratings usually shifts linearly while a transverse load (a pressure) is applied. Thus various grating-based pressure sensors have been developed to measure the applied transverse load [87, 145-150]. Pressure sensors based on conversional UV-laserinduced gratings usually, however, fail to determine the direction of the applied force due to their symmetric transverse-loading characteristics. The $\mathrm{CO}_{2}$-laser-induced LPFGs exhibit asymmetric transverse-loading characteristics due to the load-induced birefringence that leads to the rotation of optical principal axes in the gratings [118, 151]. As shown in Fig. 19, the responses of resonant wavelength of the $\mathrm{CO}_{2}$-laser-induced LPFG to an applied transverse load depend strongly on the directions of the load, whereas those of the peak transmission attenuation are independent on the loading directions [118]. It is can be seen from Fig. 20 that, while a transverse load is applied to a $\mathrm{CO}_{2}$ laser-laser-induced LPFG along different orientations of the grating, the resonant wavelength may be shifted linearly toward the longer wavelength, the shorter wavelength, or hardly shifted, whereas the absolute value of peak transmission attenuation is linearly decreased with an increase of the applied transverse load, with almost no sensitivity to the loading direction [118]. Hence, such a $\mathrm{CO}_{2}$-laser-induced LPFG can be used to develop a promising pressure sensor that can, not only measure the pressure strain applied to engineering structures, but also determine the direction of the applied pressure [118]. A similar pressure sensor was also demonstrated to realize simultaneous measurement of a transverse load (pressure) and its orientation by the use of a FBG written in a multicore fiber [152]. Similar orientation dependence of the transverse-loading characteristics also was observed in FBGs written in the Ge-doped microstructured optical fibers [87, 150]. A twisted $\mathrm{CO}_{2}$-laser-induced LPFG can weaken the strong orientation-dependence of the transverse load and enhance the transverse-load sensitivity considerably, when compared with a torsion-free LPFG, offering the potential for use as a dynamic load sensor by means of simple intensity detection [151].
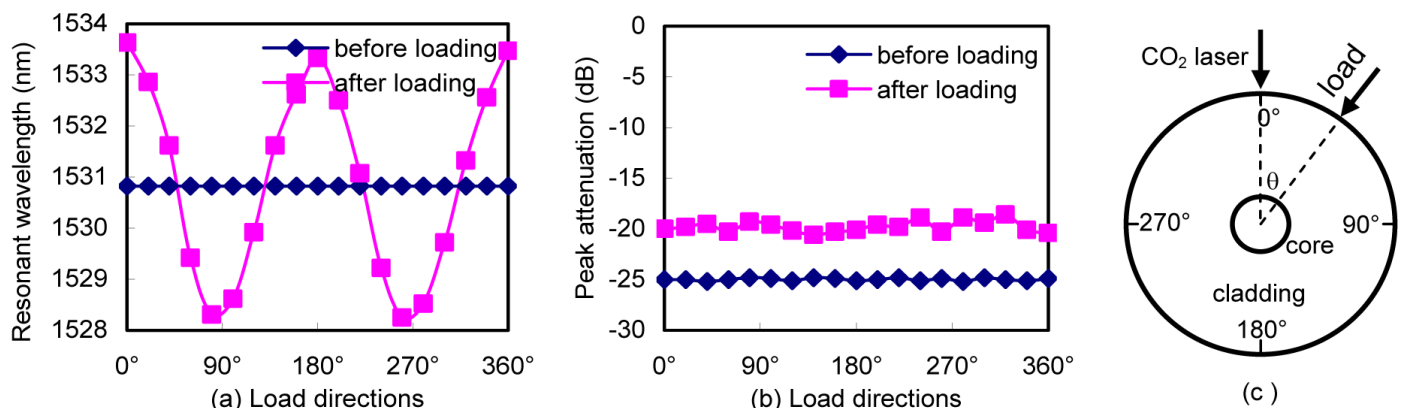

Fig. 19 (a) Resonant wavelength (b) peak transmission attenuation of the $\mathrm{CO}_{2-}$ laser-induced LPFG before and after a constant transverse load of $820.75 \mathrm{~N} \cdot \mathrm{m}^{-1}$ is applied to the grating along different fiber orientations illustrated by an angle of $\theta$ in (c), where the direction of $\mathrm{CO}_{2}$ laser irradiation is defined as the $0^{\circ}$ orientation at the circle of the LPFG [118]. 

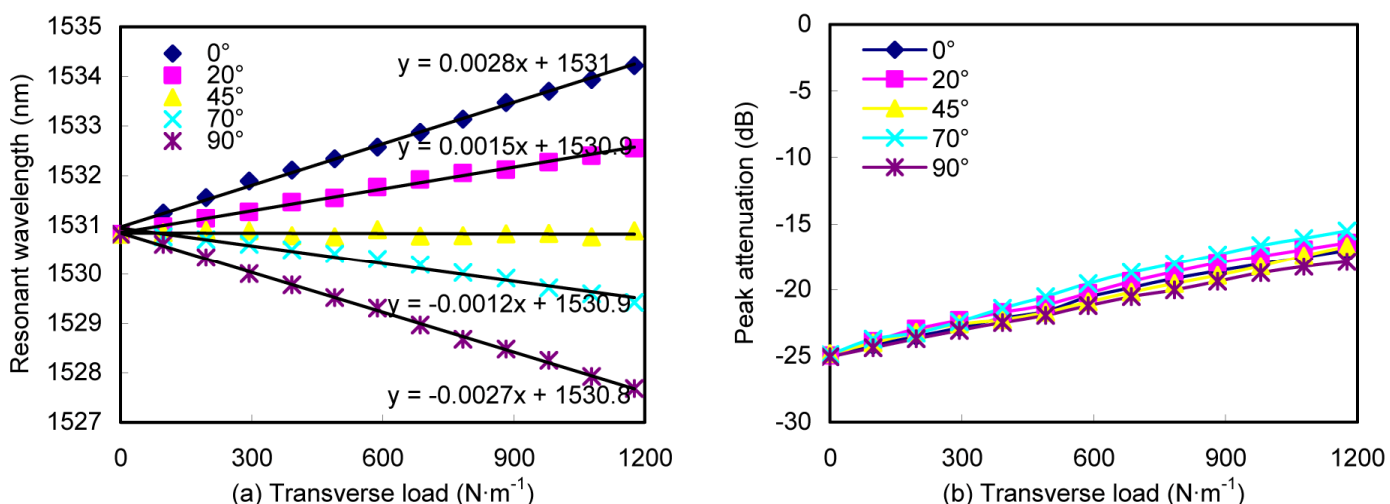

Fig. 20 (a) Resonant wavelength and (b) peak transmission attenuation of the $\mathrm{CO}_{2}$-laser-induced LPFG as functions of the transverse load applied along orientations of $0^{\circ}, 20^{\circ}, 45^{\circ}, 70^{\circ}$, and $90^{\circ}$ on the grating [118].

For health monitoring of engineering structures and civil infrastructures, measurement accuracy is often affected by the cross-sensitivity between temperature and transverse loading; hence, simultaneous measurement of temperature and transverse loading using a single sensor element is very attractive from the practical point of view. It is interesting to see from Fig. 20 that the resonant wavelength is insensitive to the loading applied to special orientations, e.g. $0^{\circ}$, while the peak transmission attenuation linearly decreases with an increase of the loading. On the other hand, as discussed above in Section VI(A), the resonant wavelength linearly shifts with temperature whereas the peak transmission attenuation hardly changes during temperature varying. Based on these unique transverse-load and temperature characteristics, a novel sensor employing a $\mathrm{CO}_{2}$-laser-induced LPFG was developed to measure simultaneously temperature and transverse loading by detecting the resonant wavelength and the peak attenuation of the grating, respectively $[21,120]$. In operation, the side, corresponding to the load-insensitive orientation, of the LPFG is mounted on the surface of a base. The applied transverse loading alters linearly the peak attenuation and hardly affects the resonant wavelength, whereas the change of temperature result in a linear shift of the resonant wavelength and has no influence on the peak attenuation. Therefore, such a sensor employing only one LPFG avoids the cross-sensitivity problem between temperature and transverse loading.

\section{F. Biochemical sensors}

Both resonant wavelength and attenuation peak of LPFGs are very sensitive to the change of external refractive index due to the dependence of the phase matching condition upon the effective refractive index of the cladding modes [7, 14]. $\mathrm{LPFG}_{\mathrm{S}}$ can thus be used for biochemical sensing based on the evanescent-wave detection principle [153-157]. As shown in Fig. 21, a promising biochemical sensor based on a LPFG written in a PCF by a $\mathrm{CO}_{2}$ laser has been demonstrated to detect the average thickness of a layer of biomolecules within a few nm [153]. By measuring the thickness the technique may thus be used for label-free detection of selective binding of biomolecules such as DNA and proteins. A detecting sensitivity of approximately $1.4 \mathrm{~nm} / 1 \mathrm{~nm}$ was achieved in terms of the shift in resonance wavelength in $\mathrm{nm}$ per $\mathrm{nm}$ thickness of biomolecule layer. The presented experiments open up new possibilities for PCFs to be used in surface chemistry studies, such as in drug discovery and as sensors in point-of-care devices and other laboratory equipment. 
a)

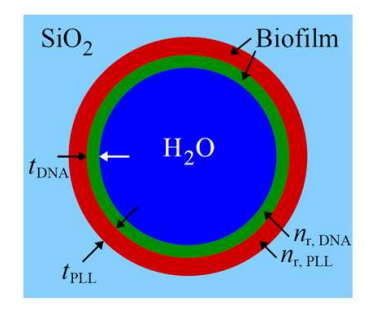

b)

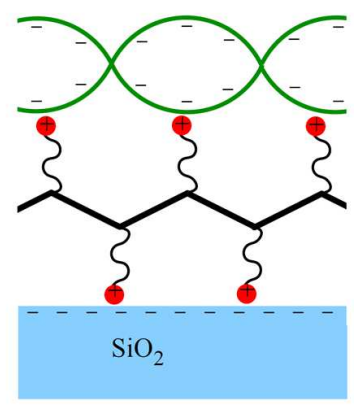

Fig. 21 Schematic diagram of biochemical sensing with a $\mathrm{CO}_{2}$-laser-induced LPFG in a PCF, (a) A hole of a PCF. The side is coated with poly-L-lysine (PLL) and DNA in monolayers of various thickness ( $t$ DNA and $t \mathrm{PLL})$ and refractive indices ( $n$ r,DNA and $n \mathrm{r}, \mathrm{PLL}$ ), (b) The molecular structure of poly-L-lysine (red \& black) with positive charges immobilized onto the negatively charged silica surface $\left(\mathrm{SiO}_{2}\right)$ [153].

Various techniques have been demonstrated to enhance the sensitivities of LPFG-based refractometers $[64,65,158]$ and to solve the cross-sensitivity between temperature and refractive index [79]. A $\mathrm{CO}_{2}$-laser-induced LPFG in a microfiber drawn by taping technique has a high sensitivity of about $1900 \mathrm{~nm} / \mathrm{RI}$ to external refractive index [68]. This value is about 60 times bigger than an in-fiber Michelson interferometer made from abrupt taper of SMF [159] and 5 times bigger than a LPFG specially designed for sensitivity enhancement [160]. Another highly sensitive refractometers based on a long-period grating in a large-mode-area PCF was reported, where the maximum sensitivity is $1500 \mathrm{~nm} /$ refractive index unit at a refractive index of 1.33 , and the minimal detectable index change is $2 \times 10^{-5}[161]$.

\section{COMMUNICATION APPLICATIONS}

The $\mathrm{CO}_{2}$-laser-induced LPFGs have found many promising applications in optical telecommunications such as band-rejection filters [5, 61, 162-164], gain equalizers for erbiumdoped fiber amplifiers (EDFAs) [6, 22, 165-167], in-fiber polarizers [25, 168], couplers [169, 170], and mode converters [171] because of their bandstop filtering capability and selective mode coupling between the fundamental mode and the cladding modes.

\section{A. Band-rejection filters}

Attenuation property of LPFGs at the desired wavelength makes them to be used as promising band-rejection filters, as shown in Fig 22. Many all-fiber band-rejection filters based on a LPFG have been reported [5, 9, 22, 172, 173]. Normal LPFG-based filters, however, allow tuning of only resonance wavelength or attenuation amplitude [5, 22, 53]. Shin et al. developed a bandwidth-tunable band-rejection filter consisting of a $\mathrm{CO}_{2}$-laser-induced helicoidal LPFG pair of opposite helicities [162], as shown in Fig. 23. Such a filter enables unique rejection bandwidth tuning over more than $14 \mathrm{~nm}$ at the rejection level of $15 \mathrm{~dB}$, with low insertion loss and PDL achieved by adjusting torsion stress. Another bandwidth-tunable band-rejection filter was demonstrated by putting a normal LPFG in series with a rotary LPFG written in a twisted single mode fiber by $\mathrm{CO}_{2}$ laser pulses [163]. As shown in Fig. 24, a bandwidth tuning of about $16.3 \mathrm{~nm}$ at a rejection level of about $15 \mathrm{~dB}$ with a low PDL of less than $0.9 \mathrm{~dB}$ was realized by applying a suitable torsion to the rotary LPFG, resulting from the wavelength splitting effect of the grating. In addition, a $\mathrm{CO}_{2}$-laser-induced LPFG with special apodization was demonstrated to achieve a filter with a top rejection bandwidth of up to $10 \mathrm{~nm}$ and a top flatness of less than $0.5 \mathrm{~dB}$ [164]. 


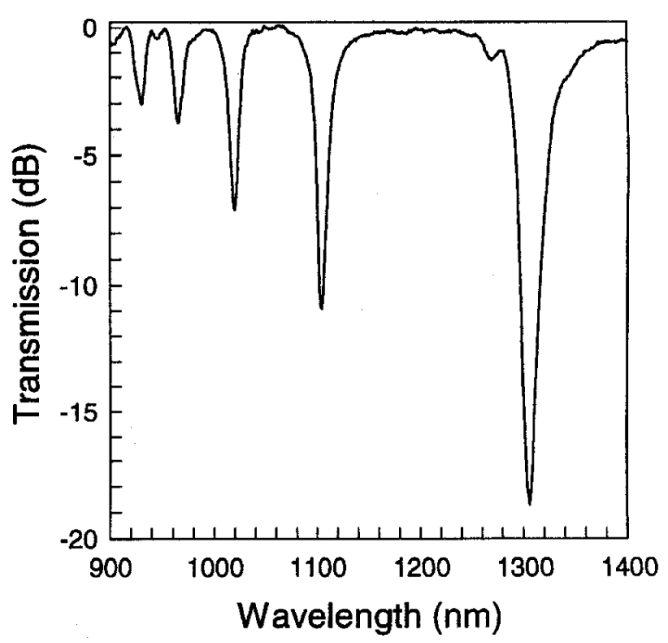

Fig. 22 Typical transmission spectrum of a LPFG in which the fundamental guided mode is coupled into forward propagating cladding modes [5].

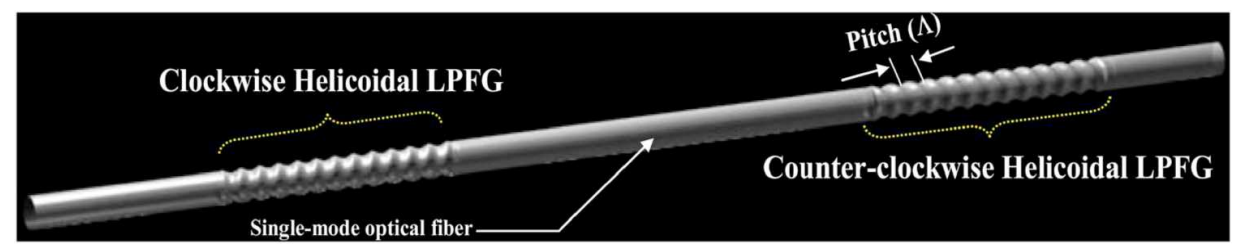

Fig. 23 Schematic of the bandwidth-tunable all-fiber band-rejection filters based on a $\mathrm{CO}_{2}$-laser-induced helicoidal LPFG pair of opposite helicities [162].

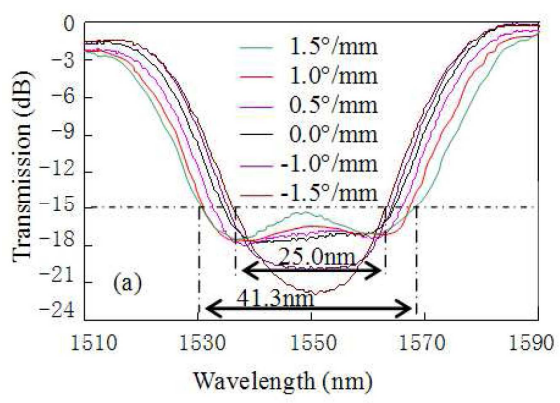

Fig. 24 Bandwidth tuning of the LPFG-based filter by applying a suitable torsion to the rotary LPFG [163].

The LPFG-based filters with an extremely deep attenuation dip recently find interesting applications, e.g. subpicosecond pulse-shaping $[174,175]$. However, the experimentally attainable level of control, especially for the coupling coefficient, usually does not allow a LPFG to reach the resonant attenuation values over $35 \mathrm{~dB}$ [176]. Fortunately, as discussed above in Section V, the peak attenuation of the $\mathrm{CO}_{2}$-laser-induced LPFGs can be enhanced to an extremely large value by applying a suitable tensile strain to obtain the optimum coupling, $k L=2 \pi$, at the resonant wavelength, where $k$ is the coupling coefficient and $L$ is the grating length $[63,133]$. For example, an extremely deep LPFG with a peak attenuation of more than $60 \mathrm{~dB}$ have been achieved to realize an exact $\pi$-phase shift at the resonance wavelength by the use of the prestrain 
technique [133]. Another interest application of $\mathrm{CO}_{2}$ laser irradiation is to produce a phase-shifted bandpass filter on a FBG [177]. Such a filter has one or multiple narrow passbands within the stopband of the FBG, depending on the position and number of the $\mathrm{CO}_{2}$ laser pulses irradiation on the FBG.

\section{B. Gain equalizers}

A typical application of LPFGs is for tunable gain equalization of EDFAs [6, 22, 165-167, 178]. However, the resonant wavelength and the attenuation amplitude of normal LPFG-based gain equalizers are changed simultaneously during tuning operation. As a result, after one parameter is adjusted, another parameter has to be readjusted. And such a readjustment usually has to be repeated many times to achieve a desired gain spectrum. Resonant wavelength of a $\mathrm{CO}_{2}$-laser-induced LPFG hardly shifts while its attenuation amplitude linearly changes with the increase of a transverse load applied to special fiber orientation [22, 119], as shown in Fig. 25. On the other hand, the attenuation amplitude of the LPFG is hardly changed while the resonant wavelength linearly shifts during temperature varying. Based on these unique temperature and transverse-load characteristics of the $\mathrm{CO}_{2}$-laser-induced LPFG, a promising tunable gain equalizer has been developed to realize dynamic gain equalization in EDFA systems [119], in which the resonant wavelength and the attenuation amplitude of the LPFG can be independently tuned by means of changing the applied load and the temperature, respectively. As shown in Fig. 26, a gain flatness of $0.5 \mathrm{~dB}$ was achieved over a bandwidth of $33 \mathrm{~nm}$ in an EDFA system by the use of such a LPFG-based gain equalizer [119].
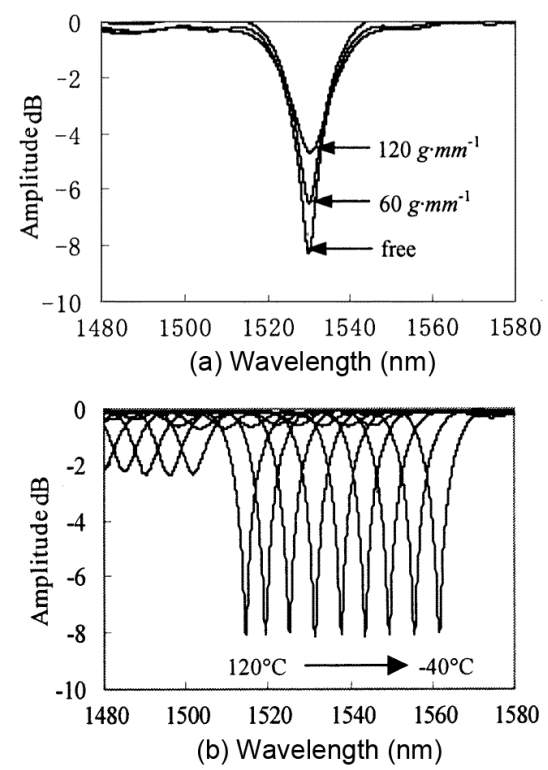

Fig. 25 Transmission spectrum evolution of a $\mathrm{CO}_{2}$-laser-induced LPFG while (a) a transverse-load is applied to the load-insensitive fiber orientation and (b) the temperature is changed [119]. 


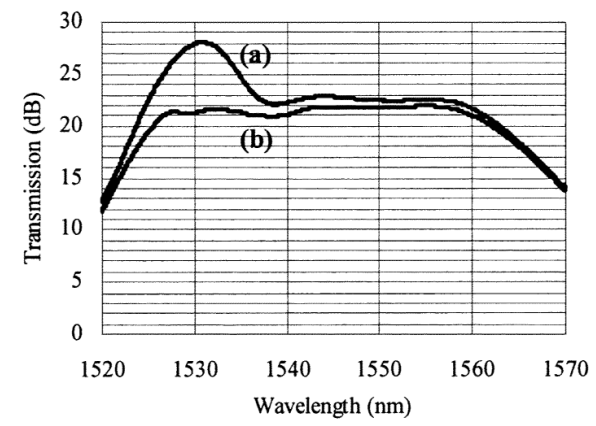

Fig. 26 Typical gain profiles of an EDFA employing a LPFG-based gain equalizer: (a) original gain spectrum; (b) flattened gain spectrum [119].

The equalization efficiency of such a dynamic gain equalizer can be enhanced by employing a twisted LPFG [165]. Another all-fiber dynamic gain equalizer based on a LPFG written in a bend-insensitive fiber was developed to flatten the gain of EDFAs by controlling the bending curvature of the LPFG directly [166]. A similar tuning technique for a LPFG-based filter was proposed in Ref. [61], in which prototype devices capable of variable attenuation at a fixed wavelength, wavelength tuning at a constant attenuation, and combinations of these spectral characteristics were demonstrated in the $\mathrm{CO}_{2}$-laser-induced LPFGs.

\section{Polarizers}

Compared with bulk waveguide polarizers, in-fiber polarizers are desirable devices in all-fiber communication systems because of their low insertion loss and compatibility with optical fiber [179-181]. As discussed above in Section IV, the $\mathrm{CO}_{2}$-laser-induced LPFGs have clear polarization dependence due to their asymmetric refractive index profile, resulting from singleside laser irradiation, within the cross-section of the gratings [23, 63, 110], thus being potential in-fiber polarizing device. Moreover, as discussed above in Section V(B), the polarization dependence of the $\mathrm{CO}_{2}$-laser-induced LPFG with periodic grooves can be greatly enhanced by applying a tensile strain [63] or increasing temperature[134]. So a promising in-fiber polarizer based on a LPFG was developed by the use of a focused $\mathrm{CO}_{2}$ laser beam to collapse or perturb periodically air holes in a pure-silica PCF [25]. In practical operation, a stretch strain is applied to the LPFG-based polarizer to enhance the polarization dependence of the grating. As a result, the maximum PDL and the maximum polarization extinction ratio of the LPFG are increased to 27.27 and $22.83 \mathrm{~dB}$, respectively, as shown in Fig. 27. Such a LPFG-based polarizer thus exhibits a high polarization extinction ratio of more than $20 \mathrm{~dB}$ over a wide wavelength range of about 11 $\mathrm{nm}$ near the communication wavelength of $1550 \mathrm{~nm}$ [25]. Moreover, this polarizer has a very low temperature sensitivity of $3.9 \mathrm{pm} /{ }^{\circ} \mathrm{C}$, which overcomes the disadvantages of the temperature sensitivity in other in-fiber polarizers created in conventional glass fibers.

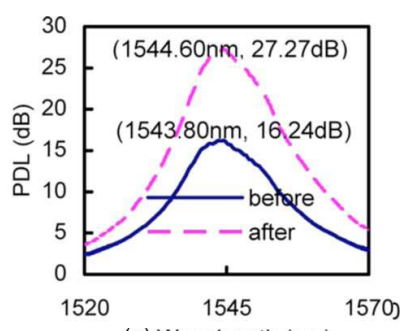

(a) Wavelength $(\mathrm{nm})$

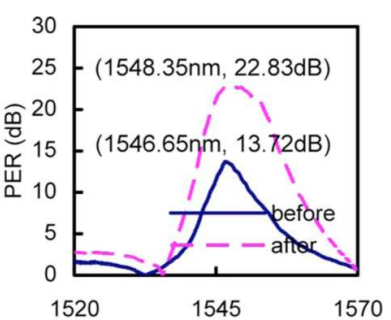

(b) Wavelength $(\mathrm{nm})$ 
Fig. 27 (a) Polarization dependent loss (PDL) and (b) polarization extinction ratio (PER) of the LPFG-based polarizer before (dashed curve) and after (solid curve) a stretch strain of $500 \mu \varepsilon$ is applied [25].

An alternative fabrication method has been developed to enhance the polarization dependence of the LPFG by the use of defocused $\mathrm{CO}_{2}$ laser pulse scanning, which is realized by moving the laser beam focus plane slightly away from the fiber cladding surface [168]. For the cascaded LPFGs fabricated by this technique, the maximum PDL obtained can be largely increased to 17.8 $\mathrm{dB}$ [168], which is larger than that reported in Ref. [182]. A rocking filter with an extinction ratio as high as $-23.5 \mathrm{~dB}$ and an insertion loss of less than $0.02 \mathrm{~dB}$ was demonstrated in a polarizationmaintaining PCF [88]. Such a filter was fabricated by periodic mechanical twisting of the fiber and heating with a scanned $\mathrm{CO}_{2}$ laser beam.

\section{Couplers}

To enhance the functionality of LPFGs, the structure of two or three parallel LPFGs has been proposed as a broadband optical coupler or optical add/drop multiplexer for applications in coarse wavelength division multiplexing systems [183-192], where light launched into one fiber is coupled into another fiber through evanescent-field coupling between the cladding modes of the two parallel gratings. All of these couplers employ gratings written by the conventional UV laser exposure technique [183-192]. Liu, et al. investigated experimentally all-fiber couplers formed by two parallel LPFGs written by high-frequency $\mathrm{CO}_{2}$-laser pulses and found asymmetrical coupling efficiency [169], as shown in Fig. 28. For gratings written in the standard SMFs with a $\mathrm{CO}_{2}$ laser, the coupling efficiency depends strongly on the fiber orientations with the strongest coupling obtained when the exposed sides of the fibers face each other. For gratings written in the borondoped SMFs with a $\mathrm{CO}_{2}$ laser, in contrast, the coupling efficiency is independent of the fiber orientation. A record-high peak coupling efficiency of about $86 \%$ was achieved in a coupler formed with two LPFGs written in boron-doped fibers by using a suitable surrounding refractive index and offset distance between such two gratings [169]. Hence, the $\mathrm{CO}_{2}$-laser-induced LPFGs in the boron-doped fiber could be employed potentially for the realization of efficient broadband optical couplers. Additionally, the $\mathrm{CO}_{2}$ laser irradiation technique can also be used to fabricate a fused fiber microcoupler with an extremely short interaction length of $200 \mu \mathrm{m}$ [19] and a FBGbased coupler [170].

(a)

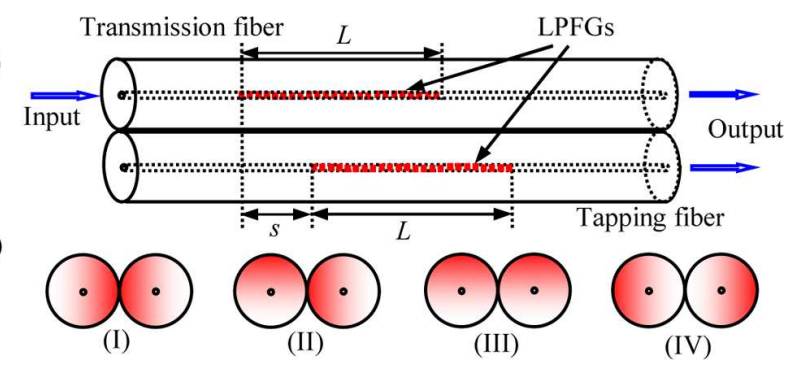

Fig. 28 (a) Schematic diagram of two parallel identical LPFGs; (b) Four different fiber orientations for the two LPFGs, in which the red areas represent the sides exposed to the $\mathrm{CO}_{2}$ laser pulses [169].

\section{CONCLUSIONS}

Compared with the UV laser exposure technique, the $\mathrm{CO}_{2}$ laser irradiation technique is much more flexible and low cost because no photosensitivity and any other pretreated process are 
required to induce a grating in the glass fibers. Moreover, the $\mathrm{CO}_{2}$ laser irradiation process can be controlled to generate complicated grating profiles via the well-known point-to-point technique without any expensive masks. The $\mathrm{CO}_{2}$ laser irradiation technique can write high-quality LPFGs in different types of optical fibers such as conventional glass fibers, solid-core photonic crystal fibers, and air-core photonic bandgap fibers. Possible mechanisms of refractive index modulations in the $\mathrm{CO}_{2}$-laser-induced LPFGs are due to residual stress relaxation, glass structure changes, and physical deformation. Single-side irradiation of $\mathrm{CO}_{2}$ laser results in asymmetrical mode coupling in the gratings. The efficiency of grating fabrications could be significantly enhanced by pre-treatment techniques, such as hydrogen loading and applying prestrain, and by post-treatment techniques such as applying tensile strain and changing temperature. The $\mathrm{CO}_{2-}$ laser-induced LPFGs have found promising sensing applications, such as temperature, strain, bend, torsion, pressure, and biochemical sensors, and communication applications such as bandrejection filters, gain equalizers, polarizers and couplers.

\section{ACKNOWLEDGMENTS}

This work was supported by a Marie Curie International Incoming Fellowship within the $7^{\text {th }}$ European Community Framework Programme, and a Foundation for the Author of National Excellent Doctoral Dissertation of PR China (No. 200940). The author gratefully acknowledges Prof. Yunjiang Rao, Prof. Tao Zhu, and Prof. Zengling Ran in Chongqing University, Prof. Wei Jin and Prof. Dongning Wang in Hong Kong Polytechnic University, and Prof. David Richardson, Dr. Gilberto Brambilla, and Dr. Marco Petrovich in University of Southampton for their contributions and cooperation during the investigations on the $\mathrm{CO}_{2}$-laser-induced LPFGs. The author also thanks Prof. Kin Seng Chiang in City University of Hong Kong and Prof. Yunqi Liu in Shanghai University for their helpful suggestions during completing this paper.

\section{REFERENCES}

1. K. O. Hill, Y. Fujii, D. C. Johnson, and B. S. Kawasaki, "Photosensitivity in optical fiber waveguides: Application to reflection filter fabrication," Appl Phys Lett 32, 647-649 (1978).

2. Y. J. Rao, "In-fibre Bragg grating sensors," Measurement Science \& Technology 8, 355-375 (1997).

3. Y. J. Rao, "Recent progress in applications of in-fibre Bragg grating sensors," Optics and Lasers in Engineering 31, 297-324 (1999).

4. A. D. Kersey, M. A. Davis, H. J. Patrick, M. LeBlanc, K. P. Koo, C. G. Askins, M. A. Putnam, and E. J. Friebele, "Fiber grating sensors," Journal of Lightwave Technology 15, 1442-1463 (1997).

5. A. M. Vengsarkar, P. J. Lemaire, J. B. Judkins, V. Bhatia, T. Erdogan, and J. E. Sipe, "Long-period fiber gratings as band-rejection filters," Journal of Lightwave Technology 14, 58-65 (1996).

6. A. M. Vengsarkar, J. R. Pedrazzani, J. B. Judkins, P. J. Lemaire, N. S. Bergano, and C. R. Davidson, "Long-period fiber-grating-based gain equalizers," Optics Letters 21, 336-338 (1996).

7. V. Bhatia, and A. M. Vengsarkar, "Optical fiber long-period grating sensors," Optics Letters 21, 692 694 (1996).

8. T. Erdogan, "Fiber grating spectra," Journal of Lightwave Technology 15, 1277-1294 (1997).

9. T. Erdogan, "Cladding-mode resonances in short- and long-period fiber grating filters," Journal of the Optical Society of America a-Optics Image Science and Vision 14, 1760-1773 (1997).

10. T. Erdogan, "Cladding-mode resonances in short- and long-period fiber grating filters (vol 14, pg 1760, 1997)," Journal of the Optical Society of America a-Optics Image Science and Vision 17, U3U3 (2000).

11. B. J. Eggleton, R. E. Slusher, J. B. Judkins, J. B. Stark, and A. M. Vengsarkar, "All-optical switching in long-period fiber gratings," Opt. Lett. 22, 883-885 (1997).

12. B. J. Eggleton, P. S. Westbrook, R. S. Windeler, S. Spalter, and T. A. Strasser, "Grating resonances in air-silica microstructured optical fibers," Optics Letters 24, 1460-1462 (1999). 
13. B. J. Eggleton, P. S. Westbrook, C. A. White, C. Kerbage, R. S. Windeler, and G. L. Burdge, "Cladding-mode-resonances in air-silica microstructure optical fibers," Journal of Lightwave Technology 18, 1084-1100 (2000).

14. S. W. James, and R. P. Tatam, "Optical fibre long-period grating sensors: Characteristics and application," Measurement Science \& Technology 14, R49-R61 (2003).

15. V. Bhatia, "Applications of long-period gratings to single and multi-parameter sensing," Optics Express 4, 457-466 (1999).

16. D. D. Davis, T. K. Gaylord, E. N. Glytsis, S. G. Kosinski, S. C. Mettler, and A. M. Vengsarkar, "Long-period fibre grating fabrication with focused $\mathrm{CO}_{2}$ laser pulses," Electronics Letters 34, 302-303 (1998).

17. D. D. Davis, T. K. Gaylord, E. N. Glytsis, and S. C. Mettler, "CO2 laser-induced long-period fibre gratings: spectral characteristics, cladding modes and polarisation independence," Electronics Letters 34, 1416-1417 (1998).

18. D. D. Davis, T. K. Gaylord, E. N. Glytsis, and S. C. Mettler, "Very-high-temperature stable $\mathrm{CO}_{2}$-laserinduced long-period fibre gratings," Electronics Letters 35, 740-742 (1999).

19. G. Kakarantzas, T. E. Dimmick, T. A. Birks, R. Le Roux, and P. S. J. Russell, "Miniature all-fiber devices based on $\mathrm{CO}_{2}$ laser microstructuring of tapered fibers," Opt. Lett. 26, 1137-1139 (2001).

20. G. Kakarantzas, T. A. Birks, and P. S. Russell, "Structural long-period gratings in photonic crystal fibers," Optics Letters 27, 1013-1015 (2002).

21. Y. J. Rao, Y. P. Wang, Z. L. Ran, and T. Zhu, "Novel fiber-optic sensors based on long-period fiber gratings written by high-frequency $\mathrm{CO}_{2}$ laser pulses," Journal of Lightwave Technology 21, 13201327 (2003).

22. Y. J. Rao, T. Zhu, Z. L. Ran, Y. P. Wang, J. Jiang, and A. Z. Hu, "Novel long-period fiber gratings written by high-frequency $\mathrm{CO} 2$ laser pulses and applications in optical fiber communication," Optics Communications 229, 209-221 (2004).

23. Y.-P. Wang, D. N. Wang, W. Jin, Y.-J. Rao, and G.-D. Peng, "Asymmetric long period fiber gratings fabricated by use of $\mathrm{CO}_{2}$ laser to carve periodic grooves on the optical fiber," Appl Phys Lett 89, 151105 (2006)

24. Y. P. Wang, L. M. Xiao, D. N. Wang, and W. Jin, "Highly sensitive long-period fiber-grating strain sensor with low temperature sensitivity," Optics Letters 31, 3414-3416 (2006).

25. Y. Wang, L. Xiao, D. N. Wang, and W. Jin, "In-fiber polarizer based on a long-period fiber grating written on photonic crystal fiber," Optics Letters 32, 1035-1037 (2007).

26. Y. Wang, W. Jin, J. Ju, H. Xuan, H. L. Ho, L. Xiao, and D. Wang, "Long period gratings in air-core photonic bandgap fibers," Optics Express 16, 2784-2790 (2008).

27. Y. Zhu, P. Shum, J.-H. Chong, M. K. Rao, and C. Lu, "Deep-notch, ultracompact long-period grating in a large-mode-area photonic crystal fiber," Optics Letters 28, 2467-2469 (2003).

28. Y. N. Zhu, P. Shum, H. W. Bay, X. Y. Chen, C. H. Tan, and C. Lu, "Wide-passband, temperatureinsensitive, and compact pi-phase-shifted long-period gratings in endlessly single-mode photonic crystal fiber," Optics Letters 29, 2608-2610 (2004).

29. Y. Liu, and K. S. Chiang, "Recent development on CO2-laser written long-period fiber gratings," Asia-Pacific Optical Communications (APOC 2008) (Hangzhou, China, Oct., 2008), Proc. SPIE Vol.7134, Paper no. 713437, 2008 (invited paper). (2008).

30. S. G. Kosinski, and A. M. Vengsarkar, "Splicer-based long-period fiber gratings," in Optical Fiber Communication Conference and Exhibit, 1998. OFC '98., Technical Digest(1998), pp. 278-279.

31. V. I. Karpov, M. V. Grekov, E. M. Dianov, K. M. Golant, S. A. Vasiliev, O. I. Medvedkov, and R. R. Khrapko, "Mode-field converters and long-period gratings fabricated by thermo-diffusion in nitrogendoped silica-core fibers," in Optical Fiber Communication Conference and Exhibit, 1998. OFC '98., Technical Digest(1998), pp. 279-280.

32. I. K. Hwang, S. H. Yun, and B. Y. Kim, "Long-period fiber gratings based on periodic microbends," Opt. Lett. 24, 1263-1265 (1999).

33. J. S. Petrovic, H. Dobb, V. K. Mezentsev, K. Kalli, D. J. Webb, and I. Bennion, "Sensitivity of LPGs in PCFs fabricated by an electric arc to temperature, strain, and external refractive index," IEEE J. of Lightwave Technology 25, 1306-1312 (2007).

34. G. Humbert, A. Malki, S. Fevrier, P. Roy, and D. Pagnoux, "Electric arc-induced long-period gratings in Ge-free air-silica microstructure fibres," Electronics Letters 39, 349-350 (2003).

35. H. Dobb, K. Kalli, and D. J. Webb, "Temperature-insensitive long period grating sensors in photonic crystal fibre," Electronics Letters 40, 657-658 (2004). 
36. G. Rego, P. V. S. Marques, H. M. Salgado, and J. L. Santos, "Simultaneous measurement of temperature and strain based on arc-induced long-period fibre gratings," Electronics Letters 41, 60-62 (2005).

37. G. M. Rego, J. L. Santos, and H. M. Salgado, "Polarization dependent loss of arc-induced long-period fibre gratings," Optics Communications 262, 152-156 (2006).

38. Y. Kondo, K. Nouchi, T. Mitsuyu, M. Watanabe, P. G. Kazansky, and K. Hirao, "Fabrication of longperiod fiber gratings by focused irradiation of infrared femtosecond laser pulses," Optics Letters $\mathbf{2 4}$, 646-648 (1999).

39. E. Fertein, C. Przygodzki, H. Delbarre, A. Hidayat, M. Douay, and P. Niay, "Refractive-index changes of standard telecommunication fiber through exposure to femtosecond laser pulses at $810 \mathrm{~cm}$," Applied Optics 40, 3506-3508 (2001).

40. A. Martinez, M. Dubov, I. Khrushchev, and I. Bennion, "Direct writing of fibre Bragg gratings by femtosecond laser," Electronics Letters 40, 1170-1172 (2004).

41. L. B. Fu, G. D. Marshall, J. A. Bolger, P. Steinvurzel, E. C. Magi, M. J. Withford, and B. J. Eggleton, "Femtosecond laser writing Bragg gratings in pure silica photonic crystal fibres," Electronics Letters 41, 638-640 (2005).

42. D. Grobnic, S. J. Mihailov, C. W. Smelser, M. Becker, and M. W. Rothhardt, "Femtosecond laser fabrication of Bragg gratings in borosilicate ion-exchange waveguides," IEEE Photonics Technology Letters 18, 1403-1405 (2006).

43. S. J. Mihailov, D. Grobnic, D. Huimin, C. W. Smelser, and B. Jes, "Femtosecond IR laser fabrication of Bragg gratings in photonic crystal fibers and tapers," IEEE Photonics Technology Letters 18, 18371839 (2006).

44. S. Savin, M. J. F. Digonnet, G. S. Kino, and H. J. Shaw, "Tunable mechanically induced long-period fiber gratings," Optics Letters 25, 710-712 (2000).

45. J. Y. Cho, and K. S. Lee, "A birefringence compensation method for mechanically induced longperiod fiber gratings," Optics Communications 213, 281-284 (2002).

46. G. Rego, "Polarization dependent loss of mechanically induced long-period fibre gratings," Optics Communications 281, 255-259 (2008).

47. T. L. S, N. A. George, P. Sureshkumar, P. Radhakrishnan, C. P. G. Vallabhan, and V. P. N. Nampoori, "Chemical sensing with microbent optical fiber," Opt. Lett. 26, 1541-1543 (2001).

48. J. L. Arce-Diego, J. Gonzalez-Garcia, D. Pereda-Cubian, and D. A. Gonzalez-Fernandez, "Optical fiber transducer based on LPFG and microbends for multi-parameter sensing," in Lasers and ElectroOptics Society, 2001. LEOS 2001. The 14th Annual Meeting of the IEEE(2001), pp. 782-783 vol.782.

49. J. W. Ham, J. H. Lee, J. Y. Cho, H. S. Jang, and K. S. Lee, "A birefringence compensation method for mechanically induced long-period fiber gratings in optical communication and sensing systems," in Optical Fiber Sensors Conference Technical Digest, 2002. OFS 2002, 15th(2002), pp. 167-170 vol.161.

50. P. Steinvurzel, E. D. Moore, E. C. Magi, B. T. Kuhlmey, and B. J. Eggleton, "Long period grating resonances in photonic bandgap fiber," Optics Express 14, 3007-3014 (2006).

51. L. Su, K. S. Chiang, and C. Lu, "Microbend-induced mode coupling in a graded-index multimode fiber," Applied Optics 44, 7394-7402 (2005).

52. C. Y. Lin, and L. A. Wang, "Loss-tunable long period fibre grating made from etched corrugation structure," Electronics Letters 35, 1872-1873 (1999).

53. C. Y. Lin, and L. A. Wang, "A wavelength- and loss-tunable band-rejection filter based on corrugated long-period fiber grating," IEEE Photonics Technology Letters 13, 332-334 (2001).

54. C. Y. Lin, L. A. Wang, and G. W. Chern, "Corrugated long-period fiber gratings as strain, torsion, and bending sensors," Journal of Lightwave Technology 19, 1159-1168 (2001).

55. C.-Y. Lin, G.-W. Chern, and L. A. Wang, "Periodical corrugated structure for forming sampled fiber Bragg grating and long-period fiber grating with tunable coupling strength," Lightwave Technology, Journal of 19, 1212-1220 (2001).

56. J. Yan, L. Qun, L. Chien-Hung, E. Lyons, I. Tomov, and H. P. Lee, "A novel strain-induced thermally tuned long-period fiber grating fabricated on a periodic corrugated silicon fixture," Photonics Technology Letters, IEEE 14, 941-943 (2002).

57. C. H. Lin, Q. Li, A. A. Au, Y. Jiang, E. R. Lyons, and H. P. Lee, "A loss tunable long-period fiber gratings on corrugated silicon with on-chip microheater and temperature sensor," in Optical Fiber Communication Conference and Exhibit, 2002. OFC 2002(2002), pp. 193-194.

58. M. Fujimaki, Y. Ohki, J. L. Brebner, and S. Roorda, "Fabrication of long-period optical fiber gratings by use of ion implantation," Opt. Lett. 25, 88-89 (2000). 
59. M. L. von Bibra, A. Roberts, and J. Canning, "Fabrication of long-period fiber gratings by use of focused ion-beam irradiation," Opt. Lett. 26, $765-767$ (2001).

60. M. L. v. Bibra, and A. Roberts., "Long period fibre gratings made with focused ion beam irradiation," 14th International Conference on Optical Fiber Sensors 604 607 (2000).

61. M. I. Braiwish, B. L. Bachim, and T. K. Gaylord, "Prototype CO2 Laser-induced Long-period Fiber Grating Variable Optical Attenuators and Optical Tunable Filters," Appl. Opt. 43, 1789-1793 (2004).

62. H. M. Chan, E. Perez, F. Alhassen, I. V. Tomov, and H. P. Lee, "Ultra-Compact Long-Period Fiber Grating and Grating Pair Fabrication using a Modulation-Scanned CO2 Laser," in Optical Fiber Communication and the National Fiber Optic Engineers Conference, 2007. OFC/NFOEC 2007. Conference on(2007), pp. 1-3.

63. Y.-P. Wang, W. Jin, and D. N. Wang, "Strain characteristics of $\mathrm{CO}_{2}$-laser-carved long period fiber gratings," Ieee J Quantum Elect 43, 101-108 (2007).

64. T. Zhu, Y.-J. Rao, J.-L. Wang, and Y. Song, "A Highly Sensitive Fiber-Optic Refractive Index Sensor Based on an Edge-Written Long-Period Fiber Grating," IEEE Photonics Technology Letters 19, 19461948 (2007).

65. T. Zhu, Y. Song, Y. Rao, and Y. Zhu, "Highly sensitive optical refractometer based on edge-written ultra-long-period fiber grating formed by periodic grooves," IEEE Sensors Journal 9, 678-681 (2009).

66. T. Zhu, and et al., "Multi-Edge-Written Long-Period Fibre Gratings with Low PDL by Using HighFrequency CO 2 Laser Pulses," Chinese Physics Letters 24, 1971 (2007).

67. S. Oh, K. R. Lee, U.-C. Paek, and Y. Chung, "Fabrication of helical long-period fiber gratings by useof a CO2 laser," Opt. Lett. 29, 1464-1466 (2004).

68. H. Xuan, W. Jin, and M. Zhang, "CO2 laser induced long period gratings in optical microfibers," Opt. Express 17, 21882-21890 (2009).

69. Y. Zhu, P. Shum, X. Chen, C.-H. Tan, and C. Lu, "Resonance-temperature-insensitive phase-shifted long-period fiber gratings induced by surface deformation with anomalous strain characteristics," Opt. Lett. 30, 1788-1790 (2005).

70. S. Lei, C. Kin Seng, and L. Chao, "CO 2 -laser-induced long-period gratings in graded-index multimode fibers for sensor applications," Photonics Technology Letters, IEEE 18, 190-192 (2006).

71. V. Grubsky, and J. Feinberg, "Rewritable densification gratings in boron-doped fibers," Opt. Lett. 30, 1279-1281 (2005).

72. Y. Liu, H. W. Lee, K. S. Chiang, T. Zhu, and Y. J. Rao, "Glass Structure Changes in $\mathrm{CO}_{2}$-Laser Writing of Long-Period Fiber Gratings in Boron-Doped Single-Mode Fibers," J. of Lightwave Technology 27, 857-863 (2009).

73. C. S. Kim, Y. Han, B. H. Lee, W. T. Han, U. C. Paek, and Y. Chung, "Induction of the refractive index change in B-doped optical fibers through relaxation of the mechanical stress," Optics Communications 185, 337-342 (2000).

74. B. H. Kim, Y. Park, T. J. Ahn, D. Y. Kim, B. H. Lee, Y. Chung, U. C. Paek, and W. T. Han, "Residual stress relaxation in the core of optical fiber by CO2 laser irradiation," Optics Letters 26, 1657-1659 (2001).

75. B. H. Kim, T.-J. Ahn, D. Y. Kim, B. H. Lee, Y. Chung, U.-C. Paek, and W.-T. Han, "Effect of CO2 Laser Irradiation on the Refractive-Index Change in Optical Fibers," Appl. Opt. 41, 3809-3815 (2002).

76. M. Yan, S. Luo, L. Zhan, Y. Wang, Y. Xia, and Z. Zhang, "Step-changed period chirped long-period fiber gratings fabricated by CO2 laser," Optics Communications 281, 2784-2788 (2008).

77. Y. Gu, K. S. Chiang, and Y. J. Rao, "Writing of Apodized Phase-Shifted Long-Period Fiber Gratings With a Computer-Controlled $\mathrm{CO}_{2}$ Laser," IEEE Photonics Technology Letters 21, 657-659 (2009).

78. T. Zhu, Y. J. Rao, and J. L. Wang, "Characteristics of novel ultra-long-period fiber gratings fabricated by high-frequency CO2 laser pulses," Optics Communications 277, 84-88 (2007).

79. T. Zhu, Y.-J. Rao, and Q.-J. Mo, "Simultaneous measurement of refractive index and temperature using a single ultralong-period fiber grating," IEEE Photonics Technology Letters 17, 2700-2702 (2005).

80. Y. J. Rao, T. Zhu, and Q. J. Mo, "Highly sensitive fiber-optic torsion sensor based on an ultra-longperiod fiber grating," Optics Communications 266, 187-190 (2006).

81. T. Hirose, K. Saito, S. Kojima, B. Yao, K. Ohsono, S. Sato, K. Takada, and A. J. Ikushima, "Fabrication of long-period fibre grating by $\mathrm{CO}_{2}$ laser-annealing in fibre-drawing process," Electronics Letters 43, 443-445 (2007).

82. G. Brambilla, V. Pruneri, L. Reekie, and D. N. Payne, "Enhanced photosensitivity in germanosilicate fibers exposed to CO2 laser radiation," Opt. Lett. 24, 1023-1025 (1999). 
83. J. C. Knight, T. A. Birks, P. S. Russell, and D. M. Atkin, "All-silica single-mode optical fiber with photonic crystal cladding," Optics Letters 21, 1547-1549 (1996).

84. C. M. Smith, N. Venkataraman, M. T. Gallagher, D. Muller, J. A. West, N. F. Borrelli, D. C. Allan, and K. W. Koch, "Low-loss hollow-core silica/air photonic bandgap fibre," Nature 424, 657-659 (2003).

85. N. Groothoff, J. Canning, E. Buckley, K. Lyttikainen, and J. Zagari, "Bragg gratings in air-silica structured fibers," Optics Letters 28, 233-235 (2003).

86. Y. Wang, H. Bartelt, M. Becker, S. Brueckner, J. Bergmann, J. Kobelke, and M. Rothhardt, "Fiber Bragg grating inscription in pure-silica and Ge-doped photonic crystal fibers," Applied Optics 48, 1963-1968 (2009).

87. Y. Wang, H. Bartelt, W. Ecke, R. Willsch, J. Kobelke, M. Kautz, S. Brueckner, and M. Rothhardt, "Sensing properties of fiber Bragg gratings in small-core Ge-doped photonic crystal fibers," Optics Communications 282, 1129-1134 (2009).

88. G. Kakarantzas, A. Ortigosa-Blanch, T. A. Birks, P. S. Russell, L. Farr, F. Couny, and B. J. Mangan, "Structural rocking filters in highly birefringent photonic crystal fiber," Optics Letters 28, 158-160 (2003).

89. Y. Zhu, P. Shum, H.-W. Bay, M. Yan, X. Yu, J. Hu, J. Hao, and C. Lu, "Strain-insensitive and hightemperature long-period gratings inscribed in photonic crystal fiber," Opt. Lett. 30, 367-369 (2005).

90. W. Shin, Y. L. Lee, T. J. Eom, B. A. Yu, and Y. C. Noh, "Temperature insensitive strain sensor based on long period fiber grating pair in photonic crystal fibers," in OptoElectronics and Communications Conference, 2009. OECC 2009. 14th(2009), pp. 1-2.

91. L. Jin, W. Jin, J. Ju, and Y. Wang, "Coupled Local-Mode Theory for Strongly Modulated Long Period Gratings," Journal of Lightwave Technology 28, 1745-1751 (2010).

92. H. W. Lee, Y. Liu, and K. S. Chiang, "Writing of Long-Period Gratings in Conventional and Photonic-Crystal Polarization-Maintaining Fibers by CO2-Laser Pulses," IEEE Photonics Technology Letters 20, 132-134 (2008).

93. Y. N. Zhu, P. Shum, J. H. Chong, M. K. Rao, and C. Lu, "Deep-notch, ultracompact long-period grating in a large-mode-area photonic crystal fiber," Optics Letters 28, 2467-2469 (2003).

94. Y. Wang, W. Jin, L. Jin, X. Tan, H. Bartelt, W. Ecke, K. Moerl, K. Schroeder, R. Spittel, R. Willsch, J. Kobelke, M. Rothhardt, L. Shan, and S. Brueckner, "Optical switch based on a fluid-filled photonic crystal fiber Bragg grating," Optics Letters 34, 3683-3685 (2009).

95. T. B. Iredale, P. Steinvurzel, and B. J. Eggleton, "Electric-arc-induced long-period gratings in fluidfilled photonic bandgap fibre," Electronics Letters 42, 739-740 (2006).

96. P. Steinvurzel, E. D. Moore, E. C. Magi, and B. J. Eggleton, "Tuning properties of long period gratings in photonic bandgap fibers," Optics Letters 31, 2103-2105 (2006).

97. B. T. Kuhlmey, B. J. Eggleton, and D. K. C. Wu, "Fluid-Filled Solid-Core Photonic Bandgap Fibers," Journal of Lightwave Technology 27, 1617-1630 (2009).

98. L. Jin, Z. Wang, Q. Fang, B. Liu, Y. Liu, G. Kai, X. Dong, and B.-O. Guan, "Bragg grating resonances in all-solid bandgap fibers," Optics Letters 32, 2717-2719 (2007).

99. L. Jin, Z. Wang, Q. Fang, Y. Liu, B. Liu, G. Kai, and X. Dong, "Spectral characteristics and bend response of Bragg gratings inscribed in all-solid bandgap fibers," Opt. Express 15, 15555-15565 (2007).

100. Y. Li, T. Wei, J. A. Montoya, S. V. Saini, X. Lan, X. Tang, J. Dong, and H. Xiao, "Measurement of $\mathrm{CO} 2$-laser-irradiation-induced refractive index modulation in single-mode fiber toward long-period fiber grating design and fabrication," Appl. Opt. 47, 5296-5304 (2008).

101. K. Morishita, and A. Kaino, "Adjusting resonance wavelengths of long-period fiber gratings by the glass-structure change," Appl. Opt. 44, 5018-5023 (2005).

102. K. Morishita, Y. Shi Feng, and Y. Miyake, "Refractive-index changes and long-period fiber gratings made by rapid solidification," in Fibre and Optical Passive Components, 2002. Proceedings of 2002 IEEE/LEOS Workshop on(2002), pp. 98-103.

103. T. Hirose, K. Saito, and K. Takada, "Mid-infrared spectroscopic detection of refractive index in $\mathrm{CO}_{2}$ laser-written long-period fibre grating," Electronics Letters 44, 1187-1188 (2008).

104. U. C. Paek, and C. R. Kurkjian, "Calculation of cooling rate and induced stresses in drawing of optical fibers," J. Am. Ceram. Soc. 58, 330-335 (1975).

105. A. J. C. Grellier, N. K. Zayer, and C. N. Pannell, "Heat transfer modelling in CO2 laser processing of optical fibres," Optics Communications 152, 324-328 (1998).

106. M. D. Nielsen, G. Vienne, J. R. Folkenberg, and A. Bjarklev, "Investigation of microdeformationinduced attenuation spectra in a photonic crystal fiber," Optics Letters 28, 236-238 (2003). 
107. G. D. VanWiggeren, T. K. Gaylord, D. D. Davis, E. Anemogiannis, B. D. Garrett, M. I. Braiwish, and E. N. Glytsis, "Axial rotation dependence of resonances in curved $\mathrm{CO}_{2}$-laser-induced long-period fibre gratings," Electronics Letters 36, 1354-1355 (2000).

108. Y. Wang, D. N. Wang, W. Jin, J. Ju, and H. L. Ho, "Mode field profile and polarization dependence of long period fiber gratings written by $\mathrm{CO}_{2}$ laser " Optics Communications 281, 2522-2525 (2008).

109. R. Slavík, "Coupling to circularly asymmetric modes via long-period gratings made in a standard straight fiber " Optics Communications 275, 90-93 (2007).

110. H. S. Ryu, Y. Park, S. T. Oh, Y. Chung, and D. Y. Kim, "Effect of asymmetric stress relaxation on the polarization-dependent transmission characteristics of a $\mathrm{CO} 2$ laser-written long- period fiber grating," Opt. Lett. 28, 155-157 (2003).

111. H. Ryu, Y. Park, and D. Kim, "Asymmetric stress distribution analysis on the polarization dependent loss in a $\mathrm{CO}_{2}$-laser-written long period fiber grating," in Optical Fiber Communications Conference, 2003. OFC 2003(2003), pp. 569-570 vol.562.

112. G. D. VanWiggeren, T. K. Gaylord, D. D. Davis, M. I. Braiwish, E. N. Glytsis, and E. Anemogiannis, "Tuning, attenuating, and switching by controlled flexure of long-period fiber gratings," Optics Letters 26, 61-63 (2001).

113. Y. P. Wang, Y. J. Rao, Z. L. Ran, T. Zhu, and X. K. Zeng, "Bend-insensitive long-period fiber grating sensors," Optics and Lasers in Engineering 41, 233-239 (2004).

114. Y.-P. Wang, and Y.-J. Rao, "A novel long period fiber grating sensor measuring curvature and determining bend-direction simultaneously," IEEE Sensors Journal 5, 839-843 (2005).

115. Y. P. Wang, and Y. J. Rao, "Long period fibre grating torsion sensor measuring twist rate and determining twist direction simultaneously," Electronics Letters 40, 164-166 (2004).

116. Y. P. Wang, and Y. Rao, "CO2-laser induced LPFG torsion characteristics depending on length of twisted fibre," Electronics Letters 40, 1101-1103 (2004).

117. Y.-P. Wang, J.-P. Chen, and Y.-J. Rao, "Torsion characteristics of long-period fiber gratings induced by high-frequency CO2 laser pulses," J. Opt. Soc. Am. B 22, 1167-1172 (2005).

118. Y. Wang, D. N. Wang, W. Jin, and Y. Rao, "Asymmetric transverse-load characteristics and polarization dependence of long-period fiber gratings written by a focused $\mathrm{CO}_{2}$ laser," Applied optics 46, 3079-3086 (2007).

119. Y. P. Wang, Y. J. Rao, Z. L. Ran, T. Zhu, and A. Z. Hu, "A novel tunable gain equalizer based on a long-period fiber grating written by high-frequency CO2 laser pulses," IEEE Photonics Technology Letters 15, 251-253 (2003).

120. Y. J. Rao, Y. P. Wang, T. Zhu, and Z. L. Ran, "Simultaneous measurement of transverse load and temperature using a single long-period fibre grating element," Chinese Physics Letters 20, 72-75 (2003).

121. S. T. Oh, W. T. Han, U. C. Paek, and Y. Chung, "Azimuthally symmetric long-period fiber gratings fabricated with $\mathrm{CO}_{2}$ laser," Microw Opt Techn Let 41, 188 - 190 (2004).

122. V. Grubsky, and J. Feinberg, "Fabrication of axially symmetric long-period gratings with a carbon dioxide laser," IEEE Photonics Technology Letters 18, 2296-2298 (2006).

123. P. J. Lemaire, R. M. Atkins, V. Mizrahi, and W. A. Reed, "High pressure $\mathrm{H}_{2}$ loading as a technique for achieving ultrahigh UV photosensitivity and thermal sensitivity in $\mathrm{GeO}_{2}$ doped optical fibres," Electronics Letters 29, 1191-1193 (1993).

124. L. Drozin, P. Y. Fonjallaz, and L. Stensland, "Long-period fibre gratings written by $\mathrm{CO}_{2}$ exposure of $\mathrm{H}_{2}$-loaded, standard fibres," Electronics Letters 36, 742-744 (2000).

125. A. D. Yablon, M. F. Yan, P. Wisk, F. V. DiMarcello, J. W. Fleming, W. A. Reed, E. M. Monberg, D. J. DiGiovanni, J. Jasapara, and M. E. Lines, "Refractive index perturbations in optical fibers resulting from frozen-in viscoelasticity," Appl Phys Lett 84, 19-21 (2004).

126. A. D. Yablon, "Optical and mechanical effects of frozen-in stresses and strains in optical fibers," IEEE J. of Selected Topics in Quantum Electronics 10, 300-311 (2004).

127. A. D. Yablon, M. F. Yan, P. Wisk, F. V. DiMarcello, J. W. Fleming, W. A. Reed, E. M. Monberg, D. J. DiGiovanni, J. R. Jasapara, and M. E. Lines, "Anomalous refractive index changes in optical fibers resulting from frozen-in viscoelastic strain," in Optical Fiber Communications Conference, 2003. OFC 2003(2003), pp. PD6-1-3 vol.3.

128. A. D. Yablon, "Optical and mechanical effects of frozen-in stresses and strains in optical fibers," Selected Topics in Quantum Electronics, IEEE Journal of 10, 300-311 (2004).

129. Y. Liu, and K. S. Chiang, "CO2 laser writing of long-period fiber gratings in optical fibers under tension," Opt. Lett. 33, 1933-1935 (2008). 
130. H. W. Lee, and K. S. Chiang, "CO2 laser writing of long-period fiber grating in photonic crystal fiber under tension," Opt. Express 17, 4533-4539 (2009).

131. H. W. Lee, and K. S. Chiang, "CO by frozen-in viscoelasticity," in Lasers and Electro-Optics 2009 and the European Quantum Electronics Conference. CLEO Europe - EQEC 2009. European Conference on(2009), pp. 1-1.

132. C. Zhang, and K. S. Chiang, " $\mathrm{CO}_{2}$ laser-written long-period fiber gratings in a Germanium-Boron codoped fiber: effects of applying tension during the writing process," IEEE Photonics Technology Letters 21, 1456-1458 (2009).

133. R. Slavik, "Extremely deep long-period fiber grating made with CO2 laser," IEEE Photonics Technology Letters 18, 1705-1707 (2006).

134. Y. Wang, W. Jin, and D. N. Wang, "Unique temperature sensing characteristics of CO2-laser-notched long-period fiber gratings," Optics and Lasers in Engineering 47, 1044-1048 (2009).

135. Y. P. Wang, Y. J. Rao, Z. L. Ran, and T. Zhu, "Unique characteristics of long-period fibre gratings fabricated by high-frequency CO2 laser pulses," Acta Physica Sinica 52, 1432-1437 (2003).

136. S. Khaliq, S. W. James, and R. P. Tatam, "Enhanced sensitivity fibre optic long period grating temperature sensor," Measurement Science \& Technology 13, $792-795$ (2002).

137. B. H. Lee, and J. Nishii, "Self-interference of long-period fibre grating and its application as temperature sensor," Electronics Letters 34, 2059-2060 (1998).

138. Y. P. Wang, D. N. Wang, and W. Jin, "CO 2 laser-grooved long period fiber grating temperature sensor system based on intensity modulation," Applied Optics 45, 7966-7970 (2006).

139. C.-L. Zhao, L. Xiao, J. Ju, M. S. Demokan, and W. Jin, "Strain and Temperature Characteristics of a Long-Period Grating Written in a Photonic Crystal Fiber and Its Application as a TemperatureInsensitive Strain Sensor," J. Lightwave Technol. 26, 220-227 (2008).

140. T. Zhu, Y.-J. Rao, Y. Song, K. S. Chiang, and M. Liu, "Highly Sensitive Temperature-Independent Strain Sensor Based on a Long-Period Fiber Grating With a $\mathrm{CO}_{2}$-Laser Engraved Rotary Structure," IEEE Photonics Technology Letters 21, 543-545 (2009).

141. T. Zhu, Y. J. Rao, J. L. Wang, and Y. Song, "Strain sensor without temperature compensation based on LPFG with strongly rotary refractive index modulation," Electronics Letters 43, 1132-1133 (2007).

142. L. Jin, W. Jin, and J. Ju, "Directional Bend Sensing With a $\mathrm{CO}_{2}$-Laser-Inscribed Long Period Grating in a Photonic Crystal Fiber," Journal of Lightwave Technology 27, 4884-4891 (2009).

143. L. A. Wang, C. Y. Lin, and G. W. Chern, "A torsion sensor made of a corrugated long period fibre grating " Measurement Science and Technology 12, 793-799 (2001).

144. T. Zhu, K. S. Chiang, Y. J. Rao, C. H. Shi, Y. Song, and M. Liu, "Characterization of Long-Period Fiber Gratings Written by $\mathrm{CO}_{2}$ Laser in Twisted Single-Mode Fibers," Lightwave Technology, Journal of 27, 4863-4869 (2009).

145. Y. Liu, L. Zhang, and I. Bennion, "Fibre optic load sensors with high transverse strain sensitivity based on long-period gratings in B/Ge co-doped fibre," Electronics Letters 35, 661-663 (1999).

146. X. Shu, K. Chisholm, I. Felmeri, K. Sugden, A. Gillooly, L. Zhang, and I. Bennion, "Highly sensitive transverse load sensing with reversible sampled fiber Bragg gratings," Appl Phys Lett 83, 3003-3005 (2003).

147. L. Bjerkan, K. Johannessen, and X. Guo, "Measurements of Bragg grating birefringence due to transverse compressive forces," The $12^{\text {th }}$ International Conference on Optical Fiber Sensors, OTuC7, 60-63 (1997).

148. C. M. Lawrence, D. V. Nelson, and E. Udd, "Measurement of transverse strains with fiber Bragg gratings," Proc. of SPIE 3042, 218-228 (1997).

149. F. Bosia, P. Giaccari, M. Facchini, J. Botsis, H. Limberger, and R. Salathe, "Characterization of embedded fibre Bragg grating sensors written in high-birefringent optical fibres subjected to transverse loading," in Smart Structures and Materials: Smart Sensor Technology and Measurement Systems, Proc. of SPIE 4694(2002), pp. 175-186.

150. Y. Wang, H. Bartelt, W. Ecke, K. Schroeder, R. Willsch, J. Kobelke, M. Rothhardt, I. Latka, and S. Brueckner, "Investigating transverse loading characteristics of microstructured fiber Bragg gratings with an active fiber depolarizer," IEEE Photonics Technology Letters 21, 1450-1452 (2009).

151. T. Zhu, Y. J. Rao, J. L. Wang, and M. Liu, "Transverse-load characteristics of twisted long-period fibre gratings written by high-frequency $\mathrm{CO}_{2}$ laser pulses," Electronics Letters 42, 451-452 (2006).

152. M. Silva-Lopez, W. N. MacPherson, C. Li, A. J. Moore, J. S. Barton, J. D. C. Jones, D. Zhao, L. Zhang, and I. Bennion, "Transverse load and orientation measurement with multicore fiber Bragg gratings," Applied Optics 44, 6890-6897 (2005). 
153. L. Rindorf, J. B. Jensen, M. Dufva, L. H. Pedersen, P. E. Hoiby, and O. Bang, "Photonic crystal fiber long-period gratings for biochemical sensing," Opt. Express 14, 8224-8231 (2006).

154. M. P. DeLisa, Z. Zhang, M. Shiloach, S. Pilevar, C. C. Davis, J. S. Sirkis, and W. E. Bentley, "Evanescent Wave Long-Period Fiber Bragg Grating as an Immobilized Antibody Biosensor," Analytical Chemistry 72, 2895-2900 (2000).

155. J. M. Fini, "Microstructure fibres for optical sensing in gases and liquids," Measurement Science \& Technology 15, 1120-1128 (2004).

156. J. B. Jensen, L. H. Pedersen, P. E. Hoiby, L. B. Nielsen, T. P. Hansen, J. R. Folkenberg, J. Riishede, D. Noordegraaf, K. Nielsen, A. Carlsen, and A. Bjarklev, "Photonic crystal fiber based evanescentwave sensor for detection of biomolecules in aqueous solutions," Optics Letters 29, 1974-1976 (2004).

157. J. Jensen, P. Hoiby, G. Emiliyanov, O. Bang, L. Pedersen, and A. Bjarklev, "Selective detection of antibodies in microstructured polymer optical fibers," Opt. Express 13, 5883-5889 (2005).

158. Y. Zhu, J. H. Chong, M. K. Rao, H. Haryono, A. Yohana, P. Shum, and C. Lu, "A long-period grating refractometer: measurements of refractive index sensitivity," in Microwave and Optoelectronics Conference, 2003. IMOC 2003. Proceedings of the 2003 SBMO/IEEE MTT-S International(2003), pp. 901-904 vol.902.

159. Z. Tian, S. S. H. Yam, and H.-P. Loock, "Refractive index sensor based on an abrupt taper Michelson interferometer in a single-mode fiber," Opt. Lett. 33, 1105-1107 (2008).

160. V. Minkovich, J. Villatoro, D. Monzon-Hernandez, S. Calixto, A. Sotsky, and L. Sotskaya, "Holey fiber tapers with resonance transmission for high-resolution refractive index sensing," Opt. Express 13, 7609-7614 (2005).

161. L. Rindorf, and O. Bang, "Highly sensitive refractometer with a photonic-crystal-fiber long-period grating," Optics Letters 33, 563-565 (2008).

162. W. Shin, B.-A. Yu, Y.-C. Noh, J. Lee, D.-K. Ko, and K. Oh, "Bandwidth-tunable band-rejection filter based on helicoidal fiber grating pair of opposite helicities," Opt. Lett. 32, 1214-1216 (2007).

163. T. Zhu, C. H. Shi, Y. J. Rao, L. L. Shi, and K. S. Chiang, "All-fiber bandwidth-tunable band-rejection filter based on a composite grating induced by CO2 laser pulses," Opt. Express 17, 16750-16755 (2009).

164. Y. J. Rao, and T. Zhu, "A novel flat-band long period grating with special apodization induced by high frequency $\mathrm{CO}_{2}$ laser pulses," in Optical Fiber Communication Conference, 2006 and the 2006 National Fiber Optic Engineers Conference. OFC 2006(2006), p. 3 pp.

165. T. Zhu, Y. J. Rao, and J. L. Wang, "All-fiber dynamic gain equalizer based on a twisted long-period grating written by high-frequency CO2 laser pulses," Appl. Opt. 46, 375-378 (2007).

166. Y. J. Rao, A. Z. Hu, and Y. C. Niu, "A novel dynamic LPFG gain equalizer written in a bendinsensitive fiber," Optics Communications 244, 137-140 (2005).

167. Y. J. Rao, T. Zhu, Z. L. Ran, and J. A. Jiang, "An all-fibre dynamic gain equalizer based on a novel long-period fibre grating written by high-frequency CO2 laser pulses," Chinese Physics Letters 19, 1822-1824 (2002).

168. M. Yang, Y. Li, and D. N. Wang, "Long-period fiber gratings fabricated by use of defocused $\mathrm{CO}_{2}$ laser beam for polarization-dependent loss enhancement," J. Opt. Soc. Am. B 26, 1203-1208 (2009).

169. Y. Liu, K. S. Chiang, Y. J. Rao, Z. L. Ran, and T. Zhu, "Light coupling between two parallel CO2laserwritten long-period fiber gratings," Opt. Express 15, 17645-17651 (2007).

170. Y. Sasaki, "Optical fiber grating couplers and their applications," in Proceedings of 2001, 3rd International Conference on Transparent Optical Networks (2001), pp. 123-126.

171. K. O. Hill, B. Malo, K. A. Vineberg, F. Bilodeau, D. C. Johnson, and I. Skinner, "Efficient mode conversion in telecommunication fibre using externally written gratings," Electronics Letters 26, 1270-1272 (1990).

172. Z. Wang, K. S. Chiang, and Q. Liu, "All-Fiber Tunable Microwave Photonic Filter Based on a Cladding-Mode Coupler," IEEE Photonics Technology Letters 22, 1241-1243.

173. Z. Wang, K. S. Chiang, and Q. Liu, "Microwave photonic filter based on circulating a cladding mode in a fiber ring resonator," Opt. Lett. 35, 769-771.

174. M. Kulishov, and J. Azana, "Long-period fiber gratings as ultrafast optical differentiators," Opt. Lett. 30, 2700-2702 (2005).

175. J. Azana, and M. Kulishov, "All-fibre ultrafast optical differentiator based on $\pi$-phase-shifted longperiod grating," Electronics Letters 41, 1368-1369 (2005).

176. M. Dubov, I. Bennion, S. A. Slattery, and D. N. Nikogosyan, "Strong long-period fiber gratings recorded at $352 \mathrm{~nm}$," Opt. Lett. 30, 2533-2535 (2005). 
177. L. Xia, P. Shum, and C. Lu, "Phase-shifted bandpass filter fabrication through $\mathrm{CO}_{2}$ laser irradiation," Optics Express 13, 5878-5882 (2005).

178. D. M. Costantini, C. A. P. Muller, S. A. Vasiliev, H. G. Limberger, and R. P. Salathe, "Tunable loss filter based on metal-coated long-period fiber grating," Photonics Technology Letters, IEEE 11, 14581460 (1999).

179. R. A. Bergh, H. C. Lefevre, and H. J. Shaw, "Single-Mode Fiberoptic Polarizer," Optics Letters 5, 479-481 (1980).

180. R. B. Dyott, J. Bello, and V. A. Handerek, "Indium-Coated D-Shaped-Fiber Polarizer," Optics Letters 12, 287-289 (1987).

181. K. M. Zhou, G. Simpson, X. F. Chen, L. Zhang, and I. Bennion, "High extinction ratio in-fiber polarizers based on 45 degrees tilted fiber Bragg gratings," Optics Letters 30, 1285-1287 (2005).

182. B. H. Lee, J. Cheong, and U.-C. Paek, "Spectral polarization-dependent loss of cascaded long-period fiber gratings," Opt. Lett. 27, 1096-1098 (2002).

183. K. S. Chiang, "Development of long-period fiber grating coupling devices," Appl. Opt. 48, F61-F67 (2009).

184. K. S. Chiang, Y. Liu, M. N. Ng, and S. Li, "Coupling between two parallel long-period fibre gratings," Electronics Letters 36, 1408-1409 (2000).

185. V. Grubsky, D. S. Starodubov, and J. Feinberg, "Wavelength-selective coupler and add-drop multiplexer using long-period fiber gratings," in Optical Fiber Communication Conference, 2000(2000), pp. 28-30 vol.24.

186. K. S. Chiang, F. Y. M. Chan, and M. N. Ng, "Analysis of two parallel long-period fiber gratings," Lightwave Technology, Journal of 22, 1358-1366 (2004).

187. F. Y. M. Chan, and K. S. Chiang, "Transfer-matrix method for the analysis of two parallel dissimilar nonuniform long-period fiber gratings," Lightwave Technology, Journal of 24, 1008-1018 (2006).

188. Y. Liu, and K. S. Chiang, "Broad-band optical coupler based on evanescent-field coupling between three parallel long-period fiber gratings," Photonics Technology Letters, IEEE 18, 229-231 (2006).

189. Y.-G. Han, S. B. Lee, C.-S. Kim, and M. Y. Jeong, "Tunable optical add-drop multiplexer based on long-period fiber gratings for coarse wavelength division multiplexing systems," Opt. Lett. 31, 703705 (2006).

190. Y. Liu, K. S. Chiang, and Q. Liu, "Symmetric 3 x 3 optical coupler using three parallel long-period fiber gratings," Opt. Express 15, 6494-6499 (2007).

191. M. J. Kim, Y. M. Jung, B. H. Kim, W.-T. Han, and B. H. Lee, "Ultra-wide bandpass filter based on long-periodfiber gratings and the evanescent field couplingbetween two fibers," Opt. Express 15, 10855-10862 (2007).

192. Y. Liu, Q. Liu, and K. S. Chiang, "Optical coupling between a long-period fiber grating and a parallel tilted fiber Bragg grating," Opt. Lett. 34, 1726-1728 (2009). 


\section{Figure captions:}

Fig. 1 Schematic diagram of a normal LPFG fabrication system based on the typical point-topoint technique employing a $\mathrm{CO}_{2}$ laser.

Fig. 2 Schematic diagram of LPFG fabrication system based on 2-dimentional scanning of focused high-frequency $\mathrm{CO}_{2}$ laser pulses [21].

Fig. 3 (a) Schematic diagram of an improved LPFG fabrication system employing a $\mathrm{CO}_{2}$ laser, (b) Operation interface of the fabrication system.

Fig. 4 Photograph of an asymmetric LPFG with periodic grooves [23].

Fig. 5 First LPFG written in a pure-silica solid-core PCF with a $\mathrm{CO}_{2}$ laser [20].

Fig. 6 Asymmetrical LPFG with periodic grooves in a pure-silica PCF [25]

Fig. 7 Cross-section image of an air-core PBF (a) before and (b) after $\mathrm{CO}_{2}$ laser irradiating, (c) side image of a LPFG written in the air-core PBF, where about two periods of the LPFG are illustrated [26].

Fig. 8 (a) Transmission spectra of six LPFGs, with different grating pitches, written in an air-core PBF, (b) the relationship between the pitch of each LPFG and the corresponding research wavelength, where two attenuation dips for each LPFG are observed from 1500 to 1680 $\mathrm{nm}$, indicating that the fundamental mode is coupled to two different higher order modes [26].

Fig. 9 (a) Calculated intensities (relative to unity incident intensity) within the cross-section of optical fiber during the single-side irradiation of $\mathrm{CO}_{2}$ laser light [107]; (b) Asymmetrical mode coupling at the resonant wavelength in the $\mathrm{CO}_{2}$-laser-induced LPFG [108].

Fig. 10 Transmission spectra of the $\mathrm{CO}_{2}$-laser-induced LPFGs in $\mathrm{H}_{2}$-loaded and untreated standard fiber (grating pitch: $450 \mathrm{~mm}$ ), (i) $\mathrm{H}_{2}$-loaded fiber with an exposure power of 0.5 $\mathrm{W}$, (ii) untreated standard fiber with an exposure power of $2.3 \mathrm{~W}$ [124].

Fig. 11 Dependence of the grating contrast on the $\mathrm{CO}_{2}$ laser energy density for LPFGs written in (a) SMF-130V and (b) SMF-28e fibers subject to different applied weights using one scanning cycle of $\mathrm{CO}_{2}$ laser irradiation $[29,129]$.

Fig. 12 Evolutions of (a) transmission spectrum and (b) polarization dependence in the $\mathrm{CO}_{2^{-}}$ laser-carved LPFG with period grooves while increasing the applied tensile strain [63]. 
Fig. 13 (a) Evolutions of (a) transmission spectra and (b) polarization dependence in the $\mathrm{CO}_{2^{-}}$ laser-carved LPFG with periodic grooves while the temperature is increased from $20{ }^{\circ} \mathrm{C}$ to $100{ }^{\circ} \mathrm{C}$ in steps of $10^{\circ} \mathrm{C}$ [134].

Fig. 14 Schematic diagram of the temperature sensor system based on intensity modulation [138].

Fig. 15 Schematic diagram of the $\mathrm{CO}_{2}$-laser-carved LPFG with asymmetric grooves (a) before and (b) after a stretching force is applied to the grating [23].

Fig.16 The shift of resonant wavelength while the $\mathrm{CO}_{2}$-laser-induced LPFG is bent to different fiber orientations [113].

Fig. 17 Schematic diagram of LPFGs sensor that can not only measure curvature but also determine bending direction, (a) sensor scheme, (b) cross section of three LPFGs [114]

Fig.18 (a) Resonant wavelength change while a $\mathrm{CO}_{2}$-laser-induced LPFG is twisted clockwise or anticlockwise [115]; (b) The response of resonant wavelength to the torsion providing the twisted fiber including a $\mathrm{CO}_{2}$-laser-induced LPFG is much longer than the grating [116].

Fig. 19 (a) Resonant wavelength (b) peak transmission attenuation of the $\mathrm{CO}_{2}$-laser-induced LPFG before and after a constant transverse load of $820.75 \mathrm{~N} \cdot \mathrm{m}^{-1}$ is applied to the grating along different fiber orientations illustrated by an angle of $\theta$ in (c), where the direction of $\mathrm{CO}_{2}$ laser irradiation is defined as the $0^{\circ}$ orientation at the circle of the LPFG [118].

Fig. 20 (a) Resonant wavelength and (b) peak transmission attenuation of the $\mathrm{CO}_{2}$-laser-induced LPFG as functions of the transverse load applied along orientations of $0^{\circ}, 20^{\circ}, 45^{\circ}, 70^{\circ}$, and $90^{\circ}$ on the grating [118].

Fig. 21 Schematic diagram of biochemical sensing with a $\mathrm{CO}_{2}$-laser-induced LPFG in a PCF, (a) A hole of a PCF. The side is coated with poly-L-lysine (PLL) and DNA in monolayers of various thickness ( $t$ DNA and $t$ PLL) and refractive indices ( $n$ r,DNA and $n \mathrm{r}, \mathrm{PLL})$, (b) The molecular structure of poly-L-lysine (red \& black) with positive charges immobilized onto the negatively charged silica surface $\left(\mathrm{SiO}_{2}\right)$ [153].

Fig. 22 Typical transmission spectrum of a LPFG in which the fundamental guided mode is coupled into forward propagating cladding modes [5].

Fig. 23 Schematic of the bandwidth-tunable all-fiber band-rejection filters based on a $\mathrm{CO}_{2}$-laserinduced helicoidal LPFG pair of opposite helicities [162].

Fig. 24 Bandwidth tuning of the LPFG-based filter by applying a suitable torsion to the rotary LPFG [163]. 
Fig. 25 Transmission spectrum evolution of a $\mathrm{CO}_{2}$-laser-induced LPFG while (a) a transverseload is applied to the load-insensitive fiber orientation and (b) the temperature is changed [119].

Fig. 26 Typical gain profiles of an EDFA employing a LPFG-based gain equalizer: (a) original gain spectrum; (b) flattened gain spectrum [119].

Fig. 27 (a) Polarization dependent loss (PDL) and (b) polarization extinction ratio (PER) of the LPFG-based polarizer before (dashed curve) and after (solid curve) a stretch strain of 500 $\mu \varepsilon$ is applied [25].

Fig. 28 (a) Schematic diagram of two parallel identical LPFGs; (b) Four different fiber orientations for the two LPFGs, in which the red areas represent the sides exposed to the $\mathrm{CO}_{2}$ laser pulses [169]. 